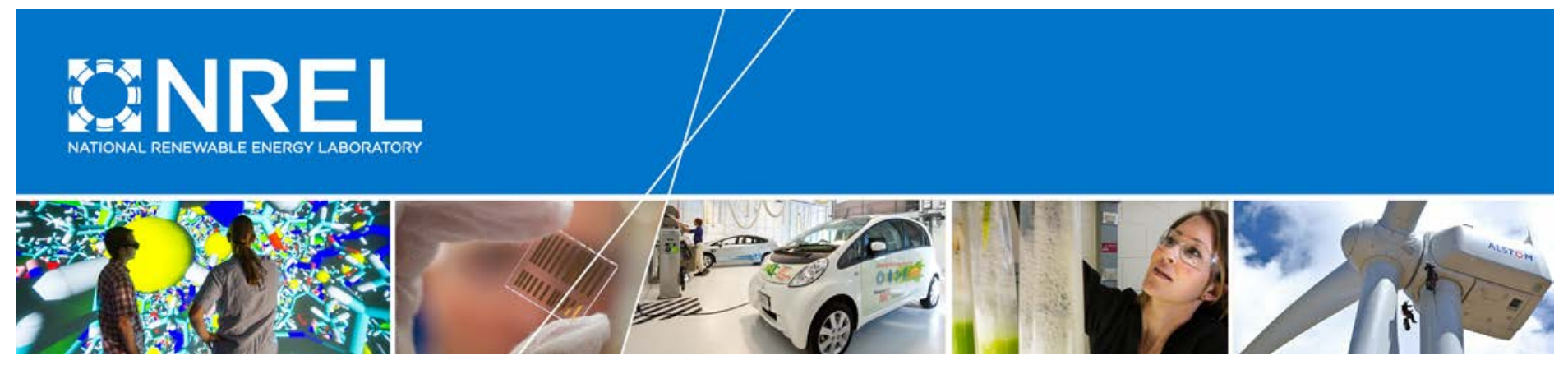

\title{
Telematics Framework for Federal Agencies: Lessons from the Marine Corps Fleet
}

Cabell Hodge and Mark Singer National Renewable Energy Laboratory

NREL is a national laboratory of the U.S. Department of Energy Office of Energy Efficiency \& Renewable Energy Operated by the Alliance for Sustainable Energy, LLC

This report is available at no cost from the National Renewable Energy Laboratory (NREL) at www.nrel.gov/publications.

Technical Report

NREL/TP-5400-70223

October 2017

Contract No. DE-AC36-08GO28308 


\section{Telematics Framework for Federal Agencies: Lessons from the Marine Corps Fleet}

Cabell Hodge and Mark Singer National Renewable Energy Laboratory

Prepared under Task No. FEMP.10960.01.01.09
NREL is a national laboratory of the U.S. Department of Energy Office of Energy Efficiency \& Renewable Energy Operated by the Alliance for Sustainable Energy, LLC

This report is available at no cost from the National Renewable Energy Laboratory (NREL) at www.nrel.gov/publications.

\section{Technical Report}

NREL/TP-5400-70223

October 2017

Contract No. DE-AC36-08GO28308
National Renewable Energy Laboratory 15013 Denver West Parkway 303-275-3000 • www.nrel.gov 


\section{NOTICE}

This report was prepared as an account of work sponsored by an agency of the United States government. Neither the United States government nor any agency thereof, nor any of their employees, makes any warranty, express or implied, or assumes any legal liability or responsibility for the accuracy, completeness, or usefulness of any information, apparatus, product, or process disclosed, or represents that its use would not infringe privately owned rights. Reference herein to any specific commercial product, process, or service by trade name, trademark, manufacturer, or otherwise does not necessarily constitute or imply its endorsement, recommendation, or favoring by the United States government or any agency thereof. The views and opinions of authors expressed herein do not necessarily state or reflect those of the United States government or any agency thereof.

This report is available at no cost from the National Renewable Energy Laboratory (NREL) at www.nrel.gov/publications.

Available electronically at SciTech Connect http:/www.osti.gov/scitech

Available for a processing fee to U.S. Department of Energy and its contractors, in paper, from:

U.S. Department of Energy

Office of Scientific and Technical Information

P.O. Box 62

Oak Ridge, TN 37831-0062

OSTI http://www.osti.gov

Phone: 865.576.8401

Fax: 865.576.5728

Email: reports@osti.gov

Available for sale to the public, in paper, from:

U.S. Department of Commerce

National Technical Information Service

5301 Shawnee Road

Alexandria, VA 22312

NTIS http://www.ntis.gov

Phone: 800.553 .6847 or 703.605 .6000

Fax: 703.605.6900

Email: orders@ntis.gov 


\section{Acknowledgments}

This work was supported by the U.S. Department of Energy, Federal Energy Management Program under Contract No. DE-AC36-08GO28308 with the National Renewable Energy Laboratory. Consultation with fleet managers and others at the U.S. Marine Corps was instrumental to the completion of this report. The authors would like to thank Daniel Robinson, James Gough, Chuck Kurnik, Margo Melendez, Jerry Davis, Karen Guerra, Brenna Thorpe, Matt Sawatzki, Courtney Dupont, Allie Erenbaum, Laura Newberger, Thomas Homan, Brendan Casey, Paul Basola, Marcus Ward, Tony Parker, Jean Pilon-Bignell, Robert Turner, Connor Bell, Timor Brik, Brock Burrows, Ron Cimo, Heidi Blakley, and all the Marine Corps fleet managers who provided anonymous feedback to the survey discussed herein. In addition, the authors would like to thank Jarett Zuboy for his diligence, responsiveness, and attention to detail while editing this report. 


\section{List of Acronyms}

AFDC

AFV

API

APN

AVL

BPA

CAN

$\mathrm{CNG}$

DHS

DOL

DTC

E85

ECU

$\mathrm{EO}$

FAST

FedRAMP

FMIS

GPS

GSA

IMEI

NREL

OBD

OECD

OEM

$\mathrm{RMF}$

VAM

VMT
Alternative Fuels Data Center

Alternative fuel vehicle

Application programming interface

Access point name

Automatic vehicle location

Blanket purchase agreement

Controller Area Network

Compressed natural gas

U.S. Department of Homeland Security

DriveCam Online

Diagnostic trouble code

A high-level ethanol blend

Engine control unit

Executive Order

Federal Automotive Statistical Tool

Federal Risk and Authorization Management Program

Fleet management information system

Global positioning system

U.S. General Services Administration

International mobile equipment identity

National Renewable Energy Laboratory

On-board diagnostic

Organisation for Economic Co-operation and Development

Original equipment manufacturer

Risk-management framework

Vehicle allocation methodology

Vehicle miles traveled 


\section{Executive Summary}

Executive Order 13693 requires federal agencies to acquire telematics for their light- and medium-duty vehicles as appropriate. This report is intended to help agencies that are deploying telematics systems and seeking to integrate them into their fleet management process. It provides an overview of telematics capabilities, lessons learned from the deployment of telematics in the Marine Corps fleet, and recommendations for federal fleet managers to maximize value from telematics.

Because the Marine Corps has about 10 years of experience with fleet telematics, the National Renewable Energy Laboratory (NREL) solicited feedback from Marine Corps fleet managers to identify best practices and lessons learned. NREL combined this knowledge with research on other telematics applications to provide guidance on how federal agencies can get the most from their telematics systems. The resulting recommendations include the following:

- Replicate the Marines Corps' DRIVESAFE program to promote safe and efficient driving behavior.

- Simplify fleet management through automated reporting and maintenance notifications.

- Use telematics in the vehicle-acquisition process to pool vehicles, determine where shuttle service could substitute for individual vehicles, or right-size and right-type the fleet in support of the vehicle allocation methodology process.

- Consult with information technology teams and experienced fleets regarding cybersecurity requirements.

Beyond the Executive Order 13693 requirements to install telematics, telematics can keep personnel safe, increase efficiency, enable fleet managers to concentrate on tasks that are higher priority than reporting, and save the federal government money. If used to their maximum extent, telematics could help fleet managers save more than $\$ 2,000$ per vehicle each year. 


\section{Table of Contents}

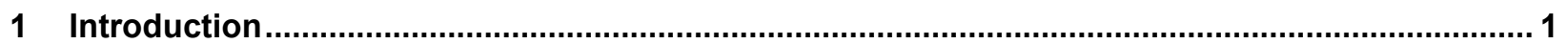

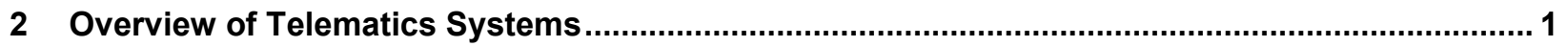

2.1 Original Equipment Manufacturer, Aftermarket, and Temporary Telematics ........................... 2

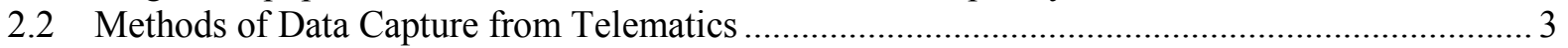

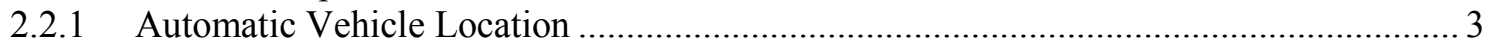

2.2.2 OBD-II Engine Data and Alternative Sources .............................................................. 4

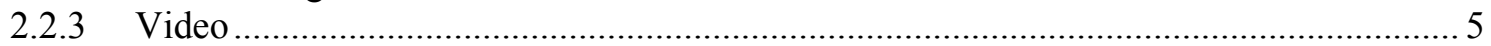

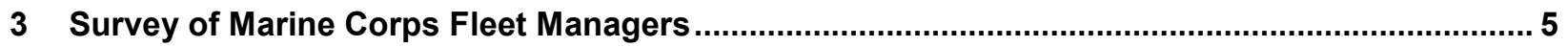

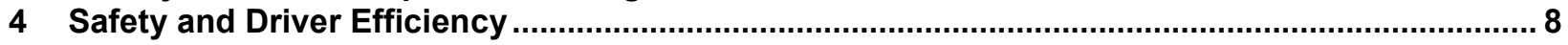

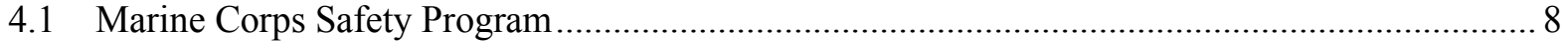

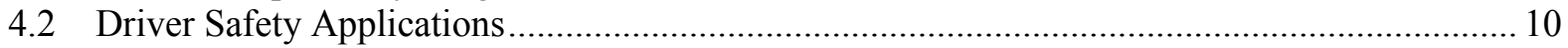

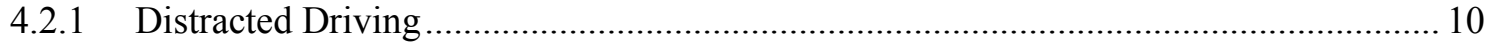

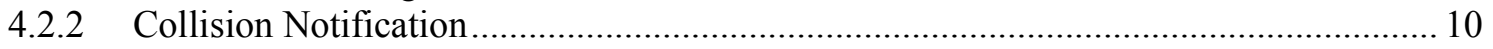

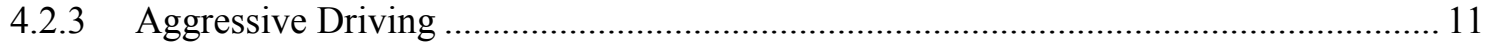

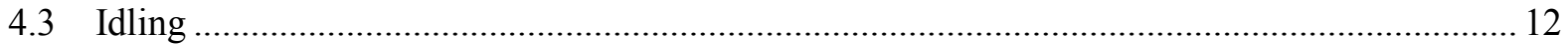

4.4 Choosing Efficient Vehicles and Reducing Vehicle Miles Traveled ...................................... 13

4.5 Cost Savings Associated with Driver Safety and Fleet Efficiency ........................................ 13

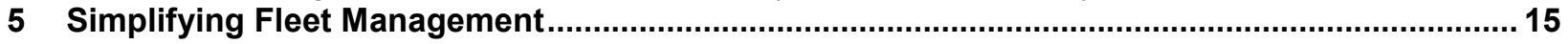

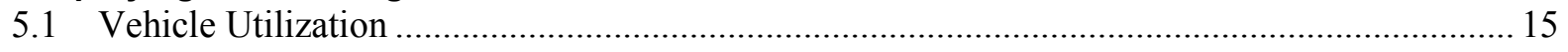

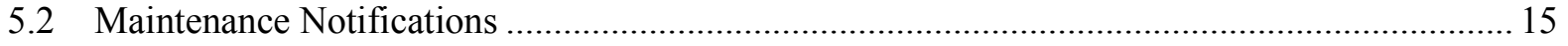

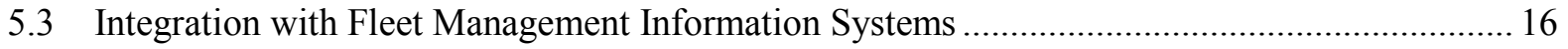

5.4 Cost Savings Associated with Simplified Fleet Management.................................................. 16

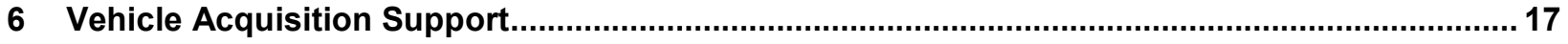

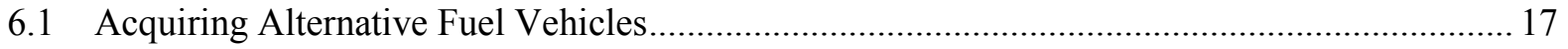

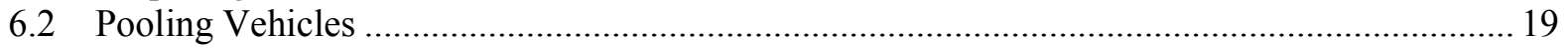

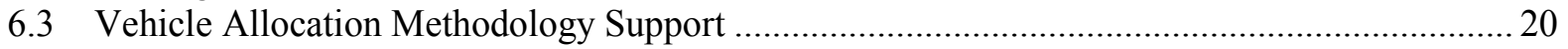

6.4 Cost Savings Associated with Optimal Vehicle Acquisition ................................................... 24

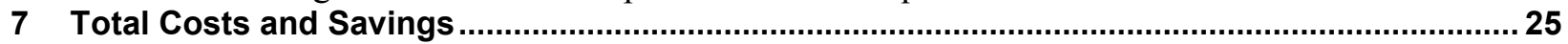

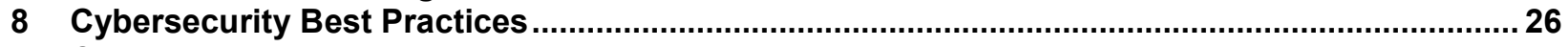

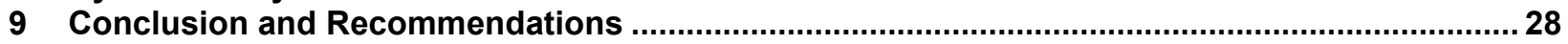

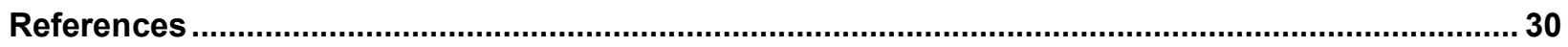

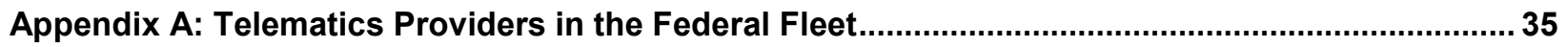

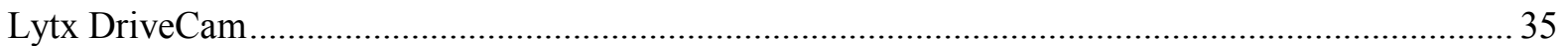

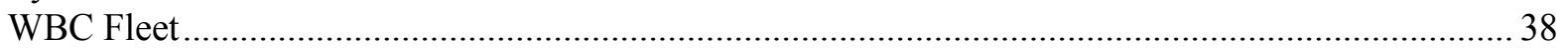

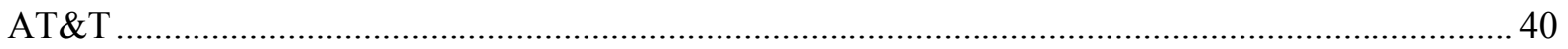

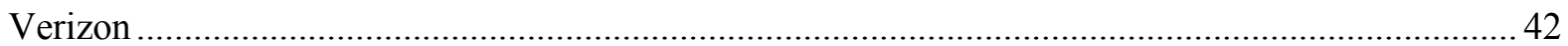




\section{List of Figures}

Figure 1. Telematics device (left, photo from CalAmp 2017) and Subaru Forester OBD-II port (right, photo by Cabell Hodge, NREL) ............................................................................................ 1

Figure 2. Percentage of OEM odometer readings supported (Geotab 2017a) ...................................... 4

Figure 3. How Verizon's NetworkFleet DTC system works (Verizon 2016) …..................................... 5

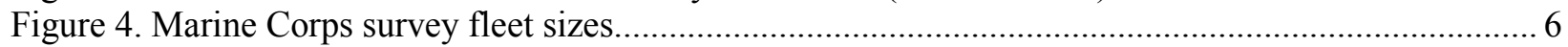

Figure 5. Proportion of non-tactical Marine Corps vehicles captured by survey ..................................... 6

Figure 6. Respondent prioritization of telematics features ( 1 as the highest priority) .............................. 7

Figure 7. Respondent prioritization of telematics applications ( 1 as the highest priority) ......................... 8

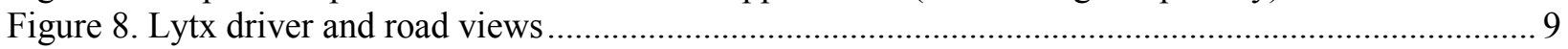

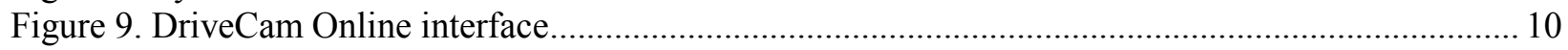

Figure 10. Single pickup truck cost savings from telematics-based efficiency program (calculated in the

Petroleum Reduction and Planning Tool, https://www.afdc.energy.gov/prep/\#) .................. 14

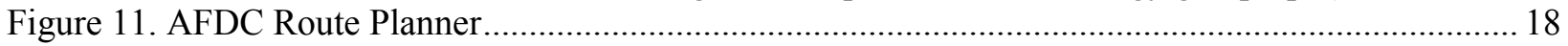

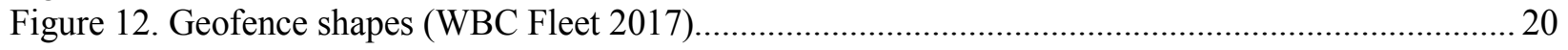

Figure 13. Risk-management framework overview (NAVFAC 2017) .................................................. 27

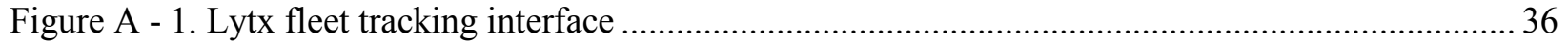

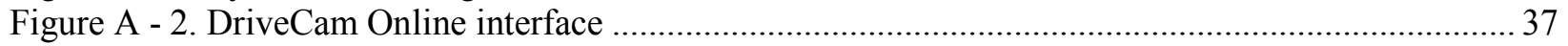

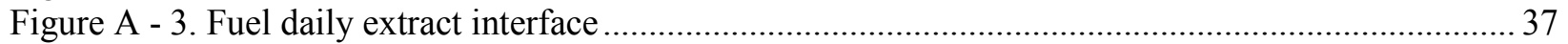

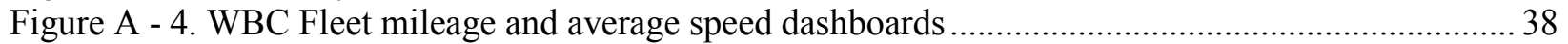

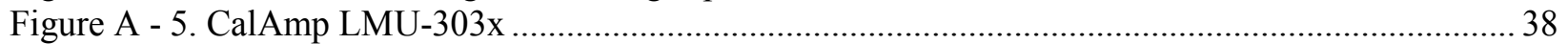

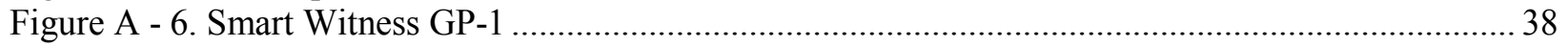

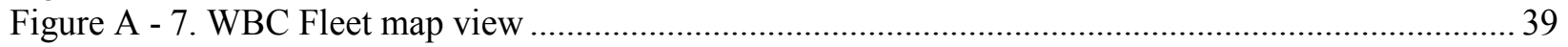

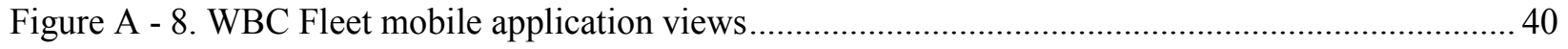

Figure A - 9. AT\&T Webtech user interfaces (AT\&T Fleet Management 2017) .................................... 41

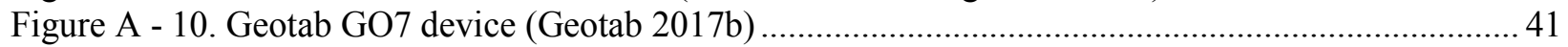

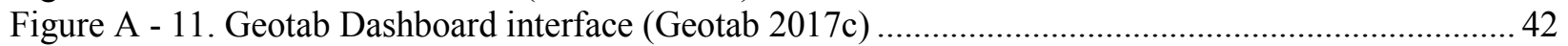

Figure A - 12. Verizon NetworkFleet vehicle location map (Automotive Fleet 2015) ............................ 44

\section{List of Tables}

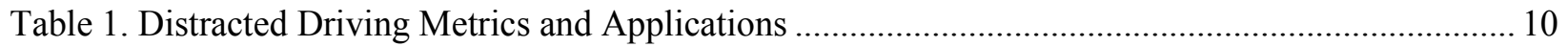

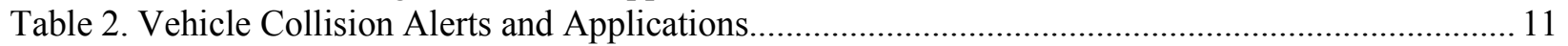

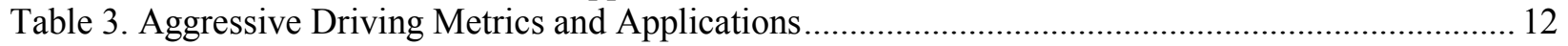

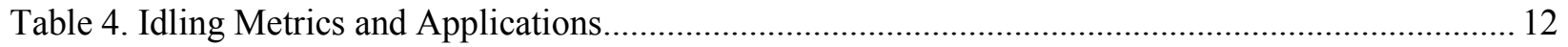

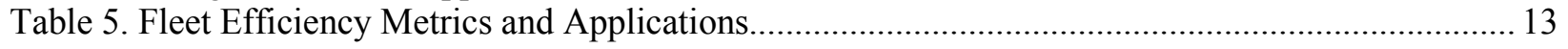

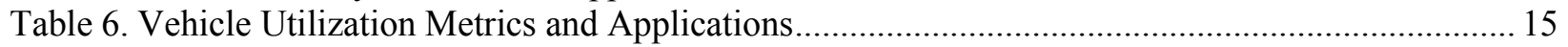

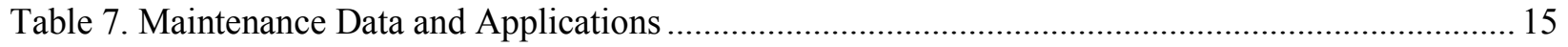

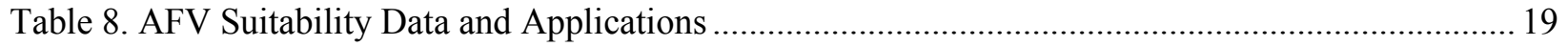

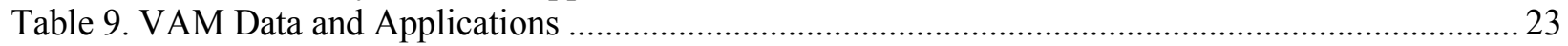

Table 10. Optimizing a Sample Fleet via Shuttling, Right-Sizing, and Pooling (Guerra et al. 2017) ........ 24

Table 11. Cost Savings from Inventory-Optimization Example......................................................... 25

Table 12. Potential Per-Vehicle Cost Savings from Telematics ........................................................... 25

Table 13. System Costs of AT\&T Telematics on GSA Schedule (AT\&T Fleet Management 2017) ........ 26 


\section{Introduction}

Executive Order (EO) 13693 requires federal agencies to deploy vehicle telematics to better utilize data and achieve fleet efficiency goals (White House 2015). As of March 2017, telematics systems must be installed in all new passenger and light-duty federal vehicle acquisitions as well as in medium-duty vehicles where appropriate. The EO also requires federal fleets to account for data in a fleet management information system (FMIS), acquire electric vehicles, and plan for fueling infrastructure, all within the context of reducing greenhouse gas emissions per mile. Telematics can simplify reporting of fleet data by automating feeds from the vehicle to an FMIS, and it can be used to plan for all types of vehicle acquisitions and to identify locations where alternative fueling infrastructure will have the greatest impact. It can also be used as part of a greater fleet management program to improve vehicle efficiency on an individual and aggregate basis. The efficiency improvements that target aggressive driving — such as excessive speeding, tight cornering, and harsh braking - also protect drivers, which is a key concern of the federal government.

The U.S. Marine Corps began implementing telematics approximately 10 years ago, and nearly three quarters of its non-tactical fleet are now equipped with telematics. As other agencies embark on their own telematics programs, they can look to the Marine Corps' experience and leadership in addition to the lessons learned from surveys of its fleet managers and studies of its telematics systems.

This report is intended to help agencies that are deploying telematics systems and seeking to integrate them into their fleet management process. It provides an overview of telematics capabilities, lessons learned from the deployment of telematics in the Marine Corps fleet, and recommendations for federal fleet managers to maximize value from telematics.

\section{Overview of Telematics Systems}

Broadly speaking, vehicle telematics use locational data and data from other sensors to display information about motor vehicle operation. Some data are based on global navigation satellite systems such as the U.S. global positioning system (GPS), while other data come from video systems, internal telematics sensors, and information from vehicle on-board diagnostic ports (OBD-I for pre-1996 vehicles or OBD-II for newer vehicles). Figure 1 shows a telematics device (left) and a vehicle OBD-II port where the device connects (right).
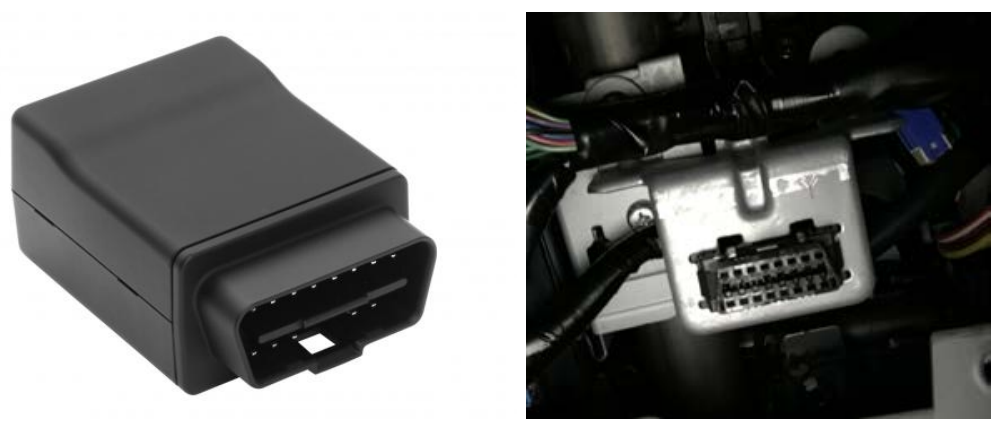

Figure 1. Telematics device (left, photo from CalAmp 2017) and Subaru Forester OBD-II port (right, photo by Cabell Hodge, NREL) 
Some telematics systems include a display within the vehicle, and all feature a desktop platform that can be reviewed from a personal computer. The vehicle display may be limited to GPS directions or may be combined in the same display with infotainment. The primary difference between telematics and infotainment is that telematics sends, receives, and stores information about location, vehicle diagnostics, collisions, speed, and emergency notifications, whereas infotainment systems provide entertainment services geared more to the consumer such as music, smart phone integration via Bluetooth, and WiFi. GPS directions could fall within either category. A deeper discussion of the differences between telematics and infotainment is available from DataOne Software (2016). Furthermore, telematics information can typically be read remotely, which goes beyond the scope of an infotainment system. Commercial telematics systems typically upload data to the cloud, where they can be reported through an internet browser, although data can be stored on a memory device within the vehicle and uploaded directly to a computer. Appendix A describes several specific telematics products that are used by federal fleets.

\subsection{Original Equipment Manufacturer, Aftermarket, and Temporary Telematics}

There are some distinctions between aftermarket and automotive original equipment manufacturer (OEM) telematics systems. OEM systems have the advantage of being programmed to read proprietary vehicle codes and access the vehicle's embedded network gateway rather than the OBD-II, which was designed for temporary devices (Gorman 2017), although aftermarket systems are developing better capabilities to read engine codes across more manufacturers via reverse-engineering of proprietary diagnostics. On the other hand, OEM telematics are brand-specific, so fleet managers with multiple vehicle makes would need to gather and combine data from each system. OEM systems are not usually as flexible as aftermarket solutions, which can be customized for fleet managers. Moreover, OEM system monthly rates tend to be more expensive than aftermarket options, although they may include 6 months or more of free service and come preinstalled (Stewart 2016). Finally, the greater integration with vehicle operation in OEM systems may make them more vulnerable to cyberattacks. For those reasons, fleets often prefer aftermarket telematics solutions, whereas an individual consumer might be content with an OEM system.

Temporary telematics systems track data for a limited time, typically to make acquisition decisions. If a fleet manager plans to replace a vehicle soon, investing in a long-term solution or paying to configure telematics with a vehicle's OBD-II might not make sense. In such a case, mobile applications used with smart phones promise a simpler solution. Smart phones can track location through GPS systems, and they contain accelerometers, magnetometers, and gyroscopes. The major drawback of mobile phone telematics is the lack of connection to the OBD-II, which makes these systems unable to read vehicle engine control unit (ECU) codes for odometer readings, diagnostic trouble codes (DTCs) for maintenance, or fuel consumption and levels (Wahlstrom and Skog 2016). However, this could also be seen as a cybersecurity advantage, because mobile phone telematics are not connected to vehicle computers, making them unlikely to compromise vehicle operation. Another potential issue is that mobile phones tend to follow the driver rather than the vehicle, but Sawatch Group has pioneered two different solutions to this issue with its Petrolr and ez-EV applications. The first is to leave the phone in the vehicle glove box for the duration of the study, and the second is to leave a Bluetooth beacon in the car 
that automatically activates the application when the phone enters the vehicle (Sawatch Group 2017).

This report focuses on long-term aftermarket telematics systems, because they are better suited to the needs of large fleets like those found in federal agencies, which have several makes and models of vehicles. Aftermarket telematics systems can include a variety of features, such as the following ${ }^{1}$ :

- Monitoring unsafe driving

- Helping reduce idling

- Tracking vehicle assets

- Setting geofences

- Providing emergency notifications

- Giving maintenance alerts

- Reading mileage

- Reporting fuel consumption

\subsection{Methods of Data Capture from Telematics}

This section discusses methods of capturing data from telematics, including automatic vehicle location (AVL), OBD-II engine data and alternative sources, and video.

\subsubsection{Automatic Vehicle Location}

One of the primary features of telematics is AVL - the ability to track mobile assets. GPS is sometimes referenced interchangeably with AVL, although technically GPS is the satellite system for capturing AVL. Fleet managers can use AVL data in the telematics interface to locate vehicles and determine the geographies in which they operate. This information can be useful in support of mission or operational logistics as well as long-term fleet planning logistics.

AVL can benefit operational logistics by allowing fleets to optimize routes. For example, fleets can use AVL to help deploy the nearest emergency response vehicle to an incident or to ascertain when a vehicle will return to a motor pool for the next user. Fleet managers can also minimize vehicle overlap, such as when delivery vehicles are operating in the same area. More basic applications include finding vehicles in unexplained locations, locating stolen vehicles, or determining collision locations.

Planning logistics also benefit from AVL data. AVL data can be used to determine which vehicles are most suitable for alternative fuels. This can involve an assessment of vehicle driving radius and daily mileage for plug-in electric vehicles or proximity to alternative fueling stations for fuels like E85 (a high-level ethanol blend), compressed natural gas (CNG), or propane. AVL

\footnotetext{
${ }^{1}$ Actual system capabilities vary by company, product, and vendor agreement. Four companies are explored in detail in Appendix A, but dozens of companies provide telematics services.
} 
data can also help determine whether fewer vehicles could perform the same functions presently performed by a fleet owing to overlapping operating geographies.

Geofence alerts rely on AVL data as well. Geofences are user-defined geographies such as a parking lot, military base, state boundary, or other area associated with a vehicle's mission. Geofence alerts identify when a vehicle has entered or exited a geofenced area. This can show when a vehicle returns to its designated parking lot where vehicles are shared among users, or it can show when a vehicle leaves its approved operating area, such as a public works van leaving a base for personal errands.

\subsubsection{OBD-II Engine Data and Alternative Sources}

Telematics can often capture vehicle miles traveled (VMT) accurately and easily. Because the systems are typically connected to the OBD-II port, they can read the odometer from vehicles if the software and vehicle are compatible. Telematics companies should have a list of compatible vehicles to show fleet managers, such as the one in Figure 2 (Geotab 2017a). An alternative is to use AVL to track the vehicle GPS data, verify it with engine operation, and generate a mileage reading accordingly (Geotab 2014). Unless the vehicle is brand new, this requires entry of a baseline odometer reading. The ability to change the odometer baseline becomes useful when using a telematics device in a second vehicle (when the telematics hardware outlives or is otherwise removed from the first vehicle). If the telematics relays mileage by reading the vehicle odometer, then the baseline problem becomes moot. It is worthwhile to consult with the telematics provider about compatibility with the vehicle odometer before installing the system, because those data tend to be more accurate and easier to capture.

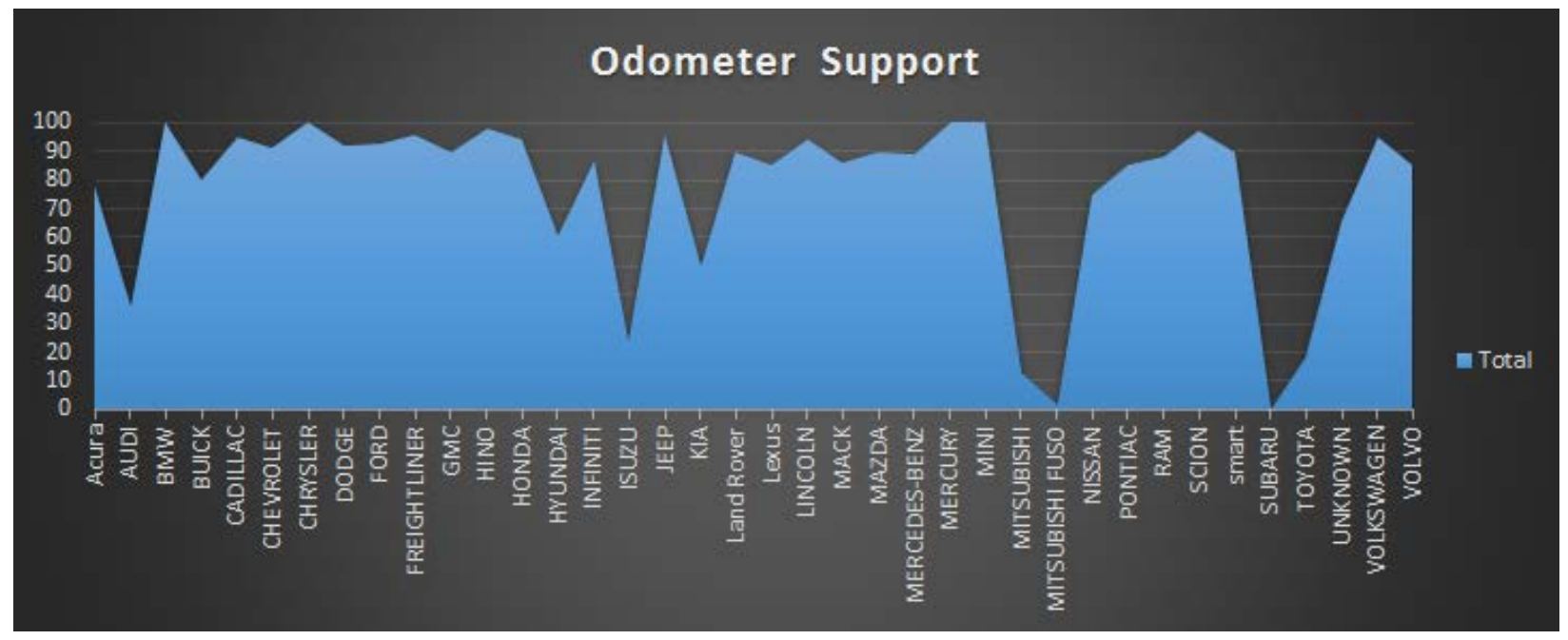

Figure 2. Percentage of OEM odometer readings supported (Geotab 2017a)

In addition, telematics systems can use the OBD-II port to read DTC alerts and assess engine issues, battery voltage, coolant temperature, powertrain malfunctions, brake failures, fuel issues, and emission sensors (Automotive Fleet 2016). Essentially, the telematics system functions like a permanent OBD-II scan tool. Fleets can even use some telematics systems to alert their mechanics to check the engine. Figure 3 shows how Verizon's NetworkFleet DTC system works. 


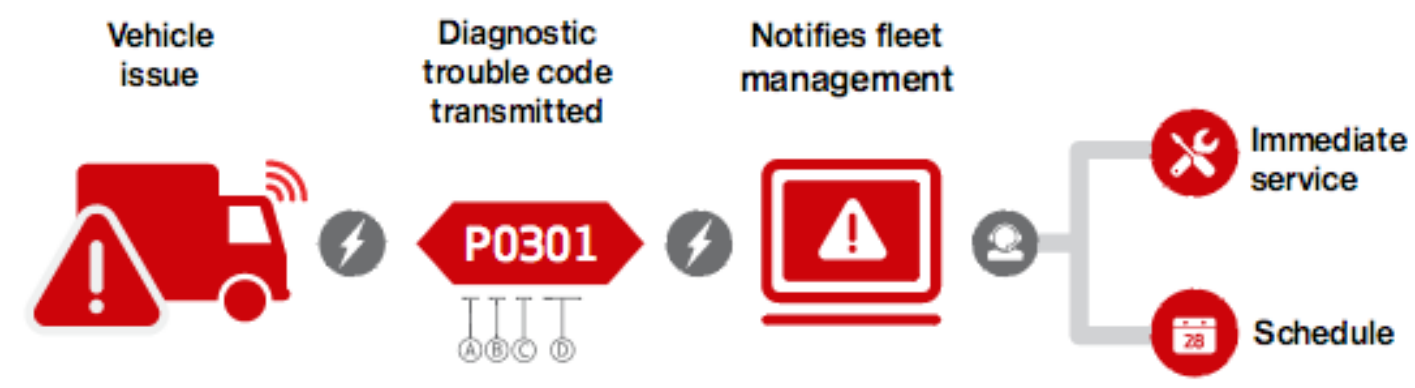

\section{DTC structure identification.}

$\begin{array}{llll}\begin{array}{l}\text { A Location of the } \\ \text { problem on the vehicle }\end{array} & \begin{array}{l}\text { B. Indicates generic } \\ \text { code or specific } \\ \text { vehicle manufacturer }\end{array} & \begin{array}{l}\text { C. Provides information } \\ \text { regarding the vehicle }\end{array} & \text { D. Specific fault index }\end{array}$

Figure 3. How Verizon's NetworkFleet DTC system works (Verizon 2016)

Some telematics systems can also track fuel levels and fuel consumption. Typically the vehicle's native sensors transmit information to the vehicle computer, and the resulting analysis can be read on the dashboard by the driver or remotely by the fleet manager using telematics (Viasat 2017). The telematics system must be able to read the fuel sensors through the OBD-II port for the vehicle in question. Alternatively, a precise fuel flow meter or fuel level sensor in the vehicle tank can enable calculation of fuel consumption over time and tracking of fueling events (Wagencontrol 2015).

To identify acceleration and braking, telematics can convert momentum changes from an accelerometer into various readings (Telogis 2014). Cornering can be measured similarly by monitoring lateral acceleration in terms of g-forces (Geotab 2016a).

\subsubsection{Video}

Some telematics systems use video recordings to capture events such as cell phone use, tobacco use, and driver fatigue. The system uses a video camera recognition program to record the incidents and transmit them to an online database, where a fleet manager can see the time and nature of the event and watch the video recording before discussing with the driver. Drivers may be resistant, but the program is designed to improve their own safety. It can also notify fleet managers and others in the event of an emergency, which can provide a faster response and lifesaving intervention. In addition, the systems can exonerate drivers when they are not at fault in a collision (Gough 2017).

\section{Survey of Marine Corps Fleet Managers}

To better understand the Marine Corps' telematics program and how their lessons apply across the federal fleet, the National Renewable Energy Laboratory (NREL) surveyed select Marine Corps fleet managers who were currently using telematics systems. NREL received responses from eight staff members who worked with fleets across six installations, including large camps, training centers, logistics bases, and air stations. Overall the Marine Corps prioritized safety features and applications, although there was significant overlap between safety-related items and those related to driving efficiency improvements. 
Respondents reported managing fleets ranging from 86 to 3,400 vehicles, and the number of telematics-enabled vehicles in a fleet ranged from 42 to 1,000 (Figure 4). In total, the respondents managed more than 6,500 vehicles, 2,300 of which had telematics installed. The Marine Corps fleet reported 11,170 vehicles in its domestic inventory in 2016 in the Federal Automotive Statistical Tool (FAST), and NREL was aware of roughly 8,100 telematics-enabled vehicles across the Lytx and WBC Fleet service customers at the time of this study. Thus, the survey covered roughly $58 \%$ of the fleet and $29 \%$ of telematics-enabled vehicles (Figure 5).

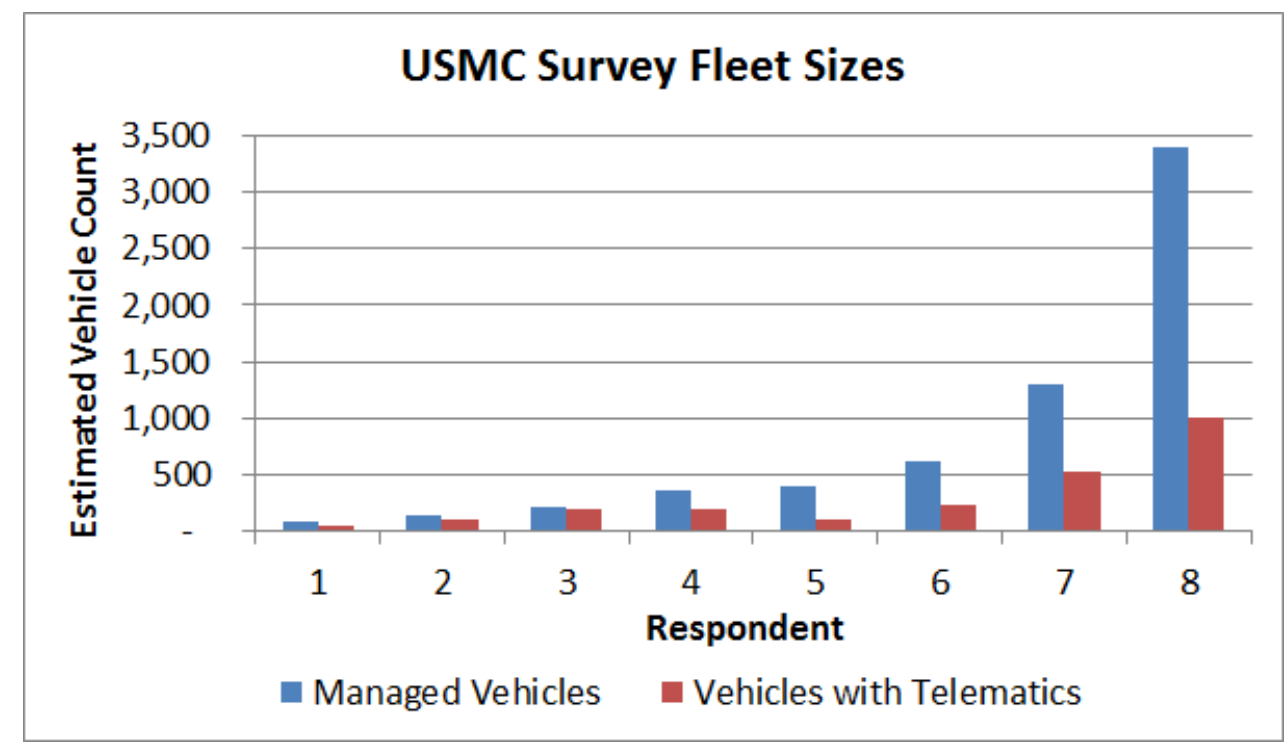

Figure 4. Marine Corps survey fleet sizes

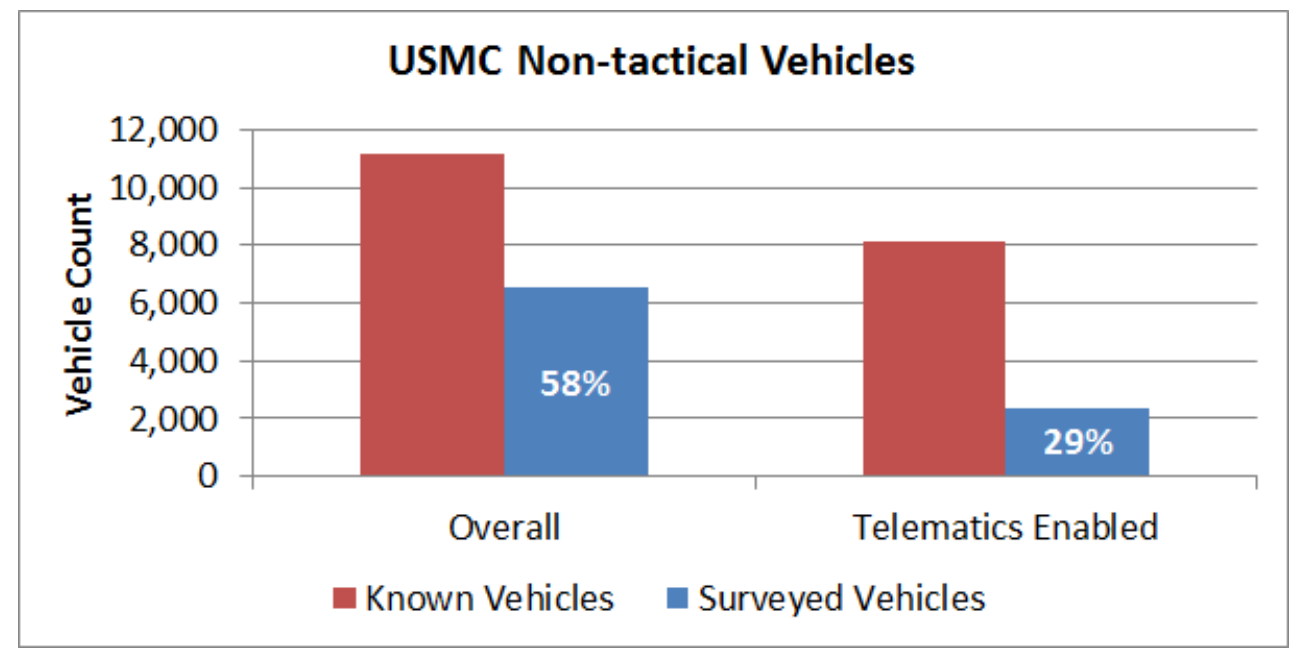

Figure 5. Proportion of non-tactical Marine Corps vehicles captured by survey

Six of the eight respondents used the Lytx DriveCam system (one of which had vehicles that used both Lytx and NetworkFleet), and two respondents used the WBC Fleet service. The respondents were generally satisfied with the tools, and all reported using the systems regularly on a daily or weekly basis. Most respondents were working to track summary trends on a monthly basis. Three managers mentioned that personnel limitations had limited their ability to track trends as often. Two respondents, including the managers using WBC Fleet, mentioned they had not yet fully implemented their telematics efforts. 
Managers were primarily using the standard speeding reports in the Lytx DriveCam Online (DOL) system and did not appear to be doing custom reporting. At least one had seen a significant reduction in speeding incidents after issuing letters to speeding drivers, reducing 10 15 violations per month to approximately one per month. All managers agreed that having realtime data is helpful in managing their fleet, because it allows them to see if vehicles are operating appropriately. The managers were using the Lytx video capabilities to highlight poor driving behaviors in support of coaching as well as to commend good driving behaviors when drivers are making good decisions that still might trigger event notifications.

Managers reported improved driving behaviors and a decrease in triggered events including speeding, cell phone use, and idling. However, several managers mentioned that the improvement depends on the drivers' leadership being engaged and coaching the drivers effectively. Respondents reported that fleet management typically reviews speeding or other event notifications along with the event video before forwarding the notices to the driver's unit command for coaching.

Respondents were asked to rate the relative importance of telematics technical features from 110 (Figure 6). Identifying speeding events was rated as the top feature for all respondents. A focus on driver safety was reflected by all the top-rated features, including collision notification, aggressive driving, and video reports. Next in the ratings was tracking of efficient driving metrics, including excessive idling and mileage tracking. Features viewed as less important included geofence violations, maintenance notifications, and GPS routing. One respondent did not rank the features, but reported that mileage, aggressive driving, collision notification, and maintenance were important while the others were not priorities.

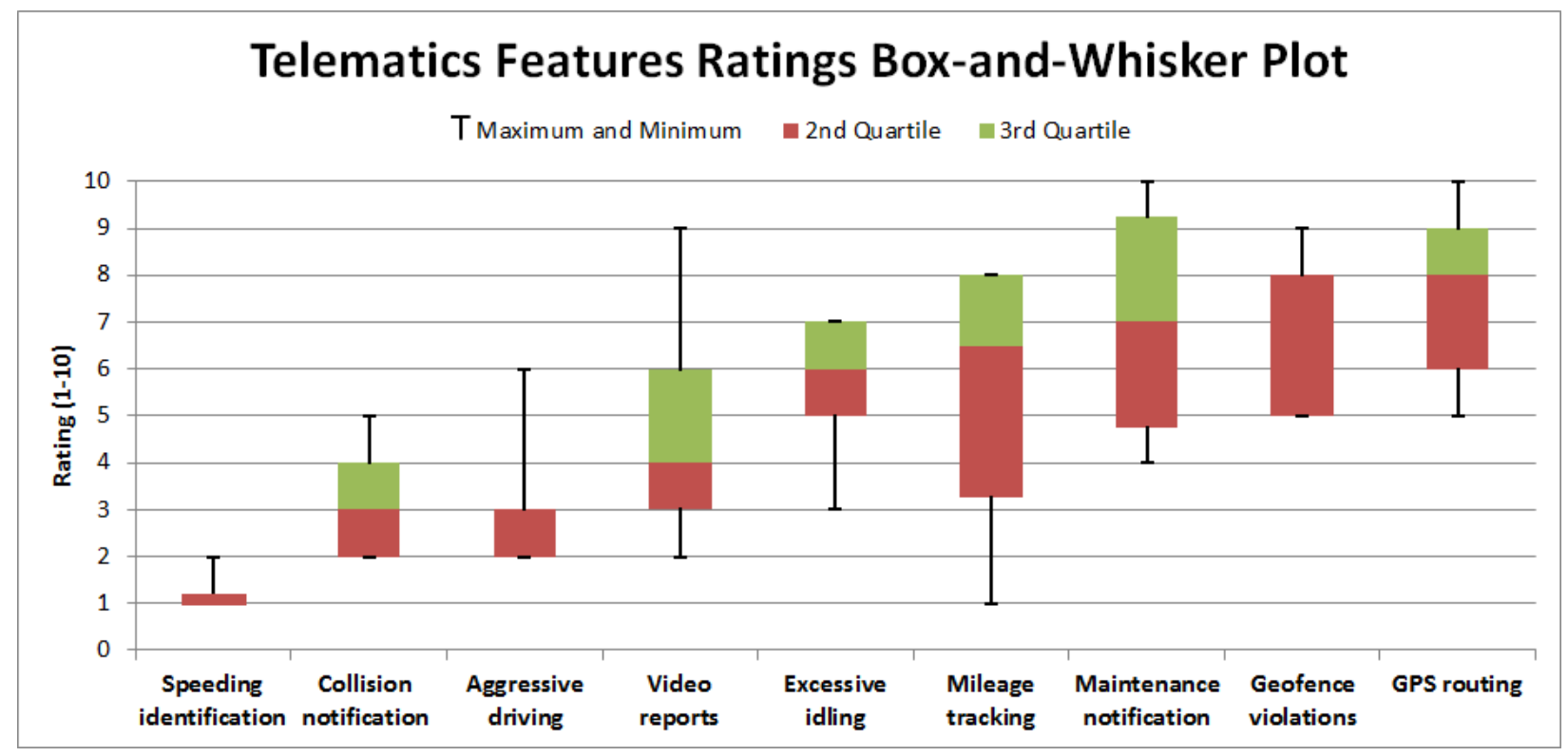

Figure 6. Respondent prioritization of telematics features (1 as the highest priority)

Respondent ratings may have been affected by the fact that the respondents' primary telematics exposure has been the Lytx system, which focuses heavily on safety. One respondent did not rank mileage tracking and maintenance because they did not have access to that information. The 
respondent and others noted that these features would be valuable, but are not currently available to them.

Respondents also ranked the relative importance of the different applications of telematics on a scale of 1-12 (Figure 7). Consistent with the rankings of telematics features, safety goals were the top priority of the fleet managers. Preventative safety enforcement, accident reporting, and assessing driver behavior were all highly rated. A large range of responses was received for the operational and fleet efficiency goals of locating vehicles, supporting required reporting, supporting maintenance, improving fuel efficiency, and supporting low-use vehicle analysis. Routing, geofencing, monitoring alternative fuel use, and vehicle acquisition analysis all lagged.

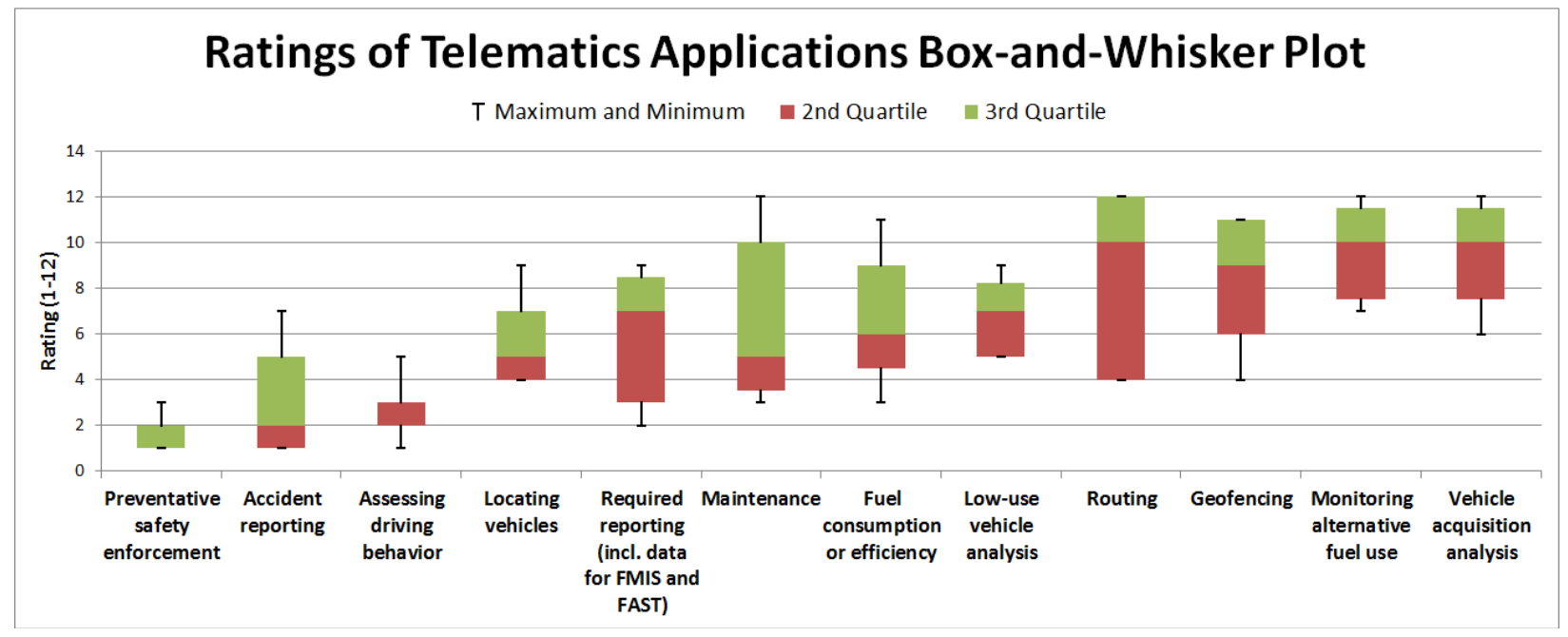

Figure 7. Respondent prioritization of telematics applications (1 as the highest priority)

The following sections use insights from the Marine Corps' telematics experience combined with research on other telematics applications to provide guidance on how federal agencies can get the most from their telematics systems.

\section{Safety and Driver Efficiency}

The Marine Corps fleet managers, telematics companies, and private fleets frequently cite improving driving behavior as one of the best applications for telematics because the systems help fleet managers simultaneously protect personnel and reduce total cost of ownership. There is significant overlap between safety and efficiency metrics, such as speeding and harsh cornering, accelerating, and braking. In addition, certain systems can capture safety-specific measures such as distracted driving and collision occurrence.

\subsection{Marine Corps Safety Program}

In 2011, the Marine Corps issued Order 5100.19F to implement DRIVESAFE, a traffic safety program designed to prevent collisions and save lives, in part responding to 23 driving fatalities in 2011 (Department of the Navy 2011, U.S. Marine Corps 2011). Among other requirements, Marine Corps installations were required to develop safety programs with training for Marines and civilians, report safety belt use, develop standard operating procedures, and maintain records. 
One of the methods for implementing this safety program is using video telematics to monitor speeding, braking, unsafe events, and vehicle collisions. This method can also notify fleet managers and others in the event of an emergency, which can provide a faster response and lifesaving intervention. The Marine Corps contracted with Lytx to install the DriveCam video system in more than 7,000 vehicles across its installations. The technology has proven valuable in various ways. The resulting information helped reduce accident damage by $35 \%$ in a 2 -year period (Lytx 2014), and it has helped reduce fuel use, carbon emissions, and idle time by up to $60 \%$ in the southwestern region (Lytx 2017). Marine Corps fleet managers can access the DriveCam dashboard to review lists of incidents and then coach individual drivers on safer driving methods. Some bases focus on this opportunity to help change driver behavior and create a safer driving culture.

Video systems like Lytx DriveCam excel at capturing events such as drivers using cell phones, smoking cigarettes, and dozing off while driving. The system uses a video camera recognition program to record the incidents and transmit them to an online database, where a fleet manager can see the time and nature of the event and watch the video recording before discussing with the driver. Several other telematics providers offer similar services or integrate with in-cab camera solutions.

The video files from the telematics have exonerated Marine drivers not at fault on numerous occasions. In the video associated with Figure 8, a Marine driver pulled into the center turn lane to turn left, and then a personally owned vehicle drifted into the center lane and hit the Marine vehicle on the left side. This video evidence helped show that the personally owned vehicle driver was at fault, enabling the Marine Corps to recoup \$10,000 in repair costs.

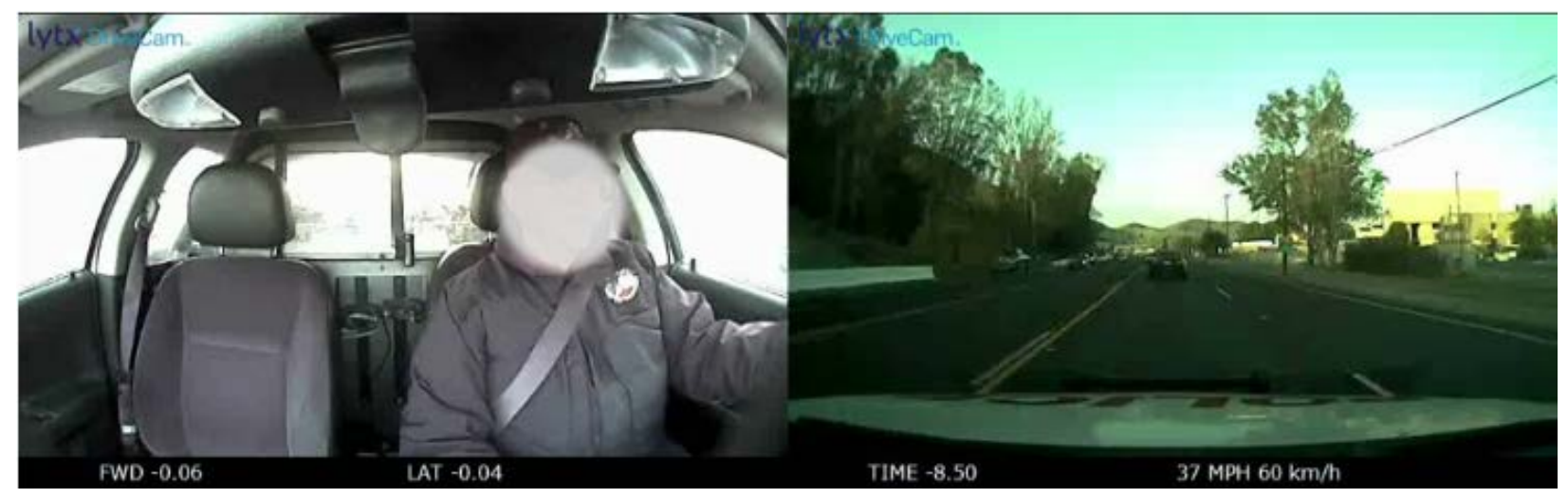

Figure 8. Lytx driver and road views

Lytx's DOL tool displays safety event listings, allows users to access specific safety event information, and allows access to the accompanying video (Figure 9). Users can navigate to summaries of events by specific drivers, vehicles, and telematics equipment units. The tool allows supervisors to log coaching efforts with drivers, enabling tracking of the effectiveness of coaching. 


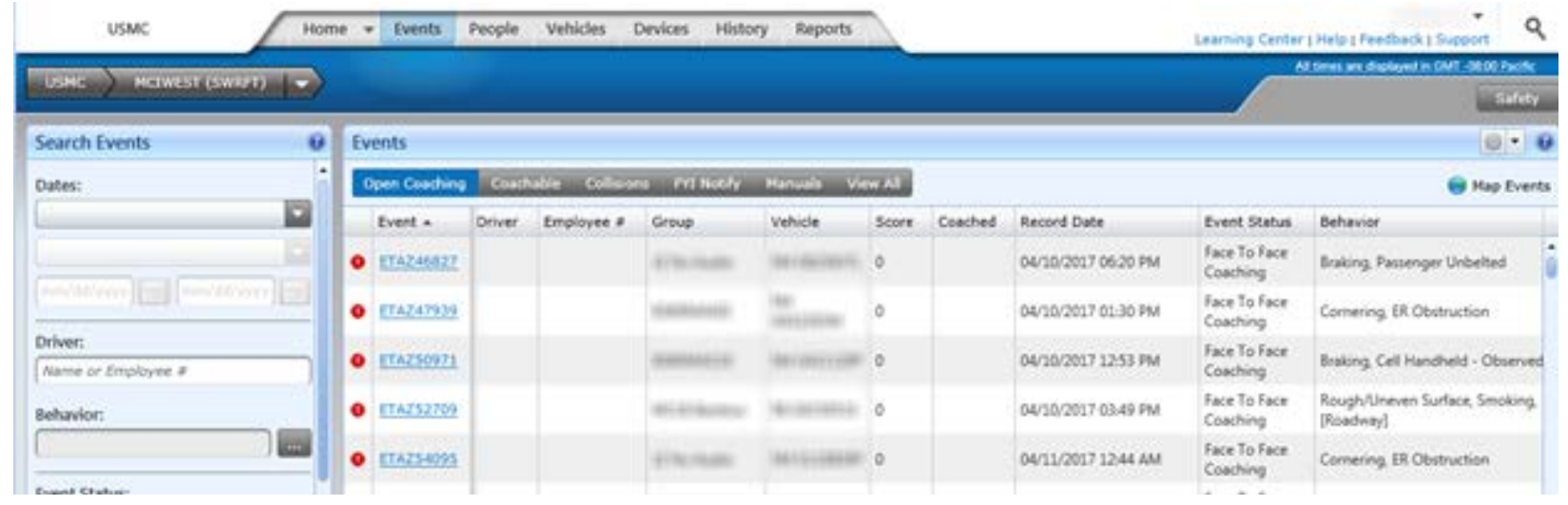

Figure 9. DriveCam Online interface

In addition to Lytx, the Marine Corps recently installed WBC Fleet telematics in 652 vehicles and has used Verizon NetworkFleet in at least one location. These other telematics solutions focus more on reports of safety and efficiency metrics than on video recordings.

\subsection{Driver Safety Applications}

Safety is a serious concern throughout the entire federal fleet. More than 20,000 collisions and driving incidents occurred in U.S. General Services Administration (GSA) vehicles in fiscal year 2014, resulting in 18 deaths (Schaubhut 2015). The following sections describe how telematics can be used to reduce collisions and prevent fatalities.

\subsubsection{Distracted Driving}

According to the National Safety Council, texting increases the rate of collisions by up to 23 times, while talking on a cell phone increases that risk by four times (National Safety Council 2017). Video telematics systems can capture incidents when drivers are texting, talking on a cell phone, smoking cigarettes, or demonstrating other inattentive behavior. As a starting point, Table 1 contains behaviors that could be tracked using telematics.

Table 1. Distracted Driving Metrics and Applications

\begin{tabular}{|c|c|c|}
\hline Data Point & Method of Data Capture & Fleet Management Application \\
\hline Texting on cell phone & & \multirow{6}{*}{$\begin{array}{l}\text { Identify unsafe driving behavior and } \\
\text { review with driver }\end{array}$} \\
\hline Talking on cell phone & & \\
\hline Eating or drinking & Video recording & \\
\hline Drowsy driving & & \\
\hline Smoking & & \\
\hline Seatbelt unfastened & $\begin{array}{l}\text { Video recording or vehicle } \\
\text { computer through OBD-II }\end{array}$ & \\
\hline
\end{tabular}

\subsubsection{Collision Notification}

Telematics systems can notify fleet managers about the occurrence of vehicle collisions. These notifications could help the fleet managers contact emergency responders or, in some cases, be set to notify 911 automatically. In addition, they are useful in minor collisions where drivers 
might otherwise not report an incident. GSA frequently observes unreported vehicle damage during inspections: $24.4 \%$ of collisions/incidents are discovered during inspection (Schaubhut 2015). Some systems can be set to notify authorities only in the case of airbag deployment. Table 2 lists vehicle collision alerts and applications.

Table 2. Vehicle Collision Alerts and Applications

\begin{tabular}{|c|c|c|c|}
\hline Data Point & Method of Data Capture & Advanced Feature & $\begin{array}{l}\text { Fleet Management } \\
\text { Application }\end{array}$ \\
\hline $\begin{array}{l}\text { Airbag } \\
\text { deployment }\end{array}$ & $\begin{array}{l}\text { Vehicle computer through } \\
\text { OBD-II or video }\end{array}$ & $\begin{array}{l}\text { Automatic notification to } \\
\text { fleet manager and/or } \\
\text { emergency services }\end{array}$ & \multirow{2}{*}{$\begin{array}{l}\text { Notify first responders in } \\
\text { the event of an } \\
\text { emergency, inform fleet } \\
\text { manager of even minor } \\
\text { collisions, and exonerate } \\
\text { drivers in cases of third- } \\
\text { party fault }\end{array}$} \\
\hline $\begin{array}{l}\text { Vehicle } \\
\text { collision } \\
\text { occurrence }\end{array}$ & $\begin{array}{l}\text { Accelerometer, vehicle } \\
\text { computer through OBD-II, or } \\
\text { video }\end{array}$ & $\begin{array}{l}\text { Video can record } \\
\text { moments before and } \\
\text { after the collision to } \\
\text { ascertain liability }\end{array}$ & \\
\hline
\end{tabular}

By geolocating collisions over time and identifying issues with road conditions, agencies can use telematics for preventive maintenance of roads in addition to vehicles. Agencies may want to adjust speed limits and install stop signs or speed bumps near areas with high rates of collisions. Fleet managers can also track the development of potholes with some telematics systems and share that information with road maintenance staff in military installation or campus settings (Jean Pilon-Bignell, Geotab, personal correspondence with author, September 19, 2017).

\subsubsection{Aggressive Driving}

To identify speeding violations, telematics systems can compare actual speeds with posted speed limits from databases. The systems often can be configured to a certain number of miles per hour over the limit and a certain duration. For example, Verizon NetworkFleet systems can issue reports reflecting an average of $10 \mathrm{mph}$ over the speed limit for more than 2 minutes. Fleet managers may find this configurability useful to reduce reports of vehicles passing tractortrailers and other excusable events. Survey results show that monitoring speeding is the highestpriority use of telematics for Marine Corps fleet managers (Figure 6).

To identify aggressive acceleration and braking, telematics can convert momentum changes from an accelerometer into various readings (Telogis 2014). Cornering can be measured similarly by monitoring lateral acceleration in terms of g-forces (Geotab 2016a). Frequent hard braking and accelerating can waste an extra 3 miles per gallon of fuel, endanger the driver and the public, damage brakes, emit unnecessary pollution, and signal a stressed-out employee (Telogis 2014). Cornering can cause many of the same issues as well as damage to the tires.

Occasional aggressive driving may be necessary, such as braking quickly to avoid an accident. Therefore, many telematics systems can be set to various degrees of leniency and number of driving events before triggering a notification. The systems may also produce an aggregate driving score, notify the driver directly, or both. For example, car2go (a public car-sharing service) displays results from its EcoScore to drivers in the form of a pleasant nature scene when driver scores are high and dying trees when drivers operate the vehicle more aggressively (car2go 2012). 
In addition to the significant safety risks, aggressive driving behaviors can reduce fuel efficiency by up to 20\% (AFDC 2017). Table 3 lists aggressive driving metrics and applications.

Table 3. Aggressive Driving Metrics and Applications

\begin{tabular}{|c|c|c|c|}
\hline Data Point & Method of Data Capture & Advanced Feature & $\begin{array}{l}\text { Fleet Management } \\
\text { Application }\end{array}$ \\
\hline Speed driven & & & \multirow{4}{*}{$\begin{array}{l}\text { - Identify unsafe } \\
\text { driving behavior } \\
\text { and review with } \\
\text { driver } \\
\text { - Combine metrics } \\
\text { into a safety or eco- } \\
\text { driving score to } \\
\text { highlight individual } \\
\text { overall } \\
\text { performance }\end{array}$} \\
\hline $\begin{array}{l}\text { Excessive } \\
\text { speed count } \\
\text { Excessive } \\
\text { speed duration }\end{array}$ & $\begin{array}{l}\text { AVL or vehicle computer } \\
\text { through OBD-II }\end{array}$ & $\begin{array}{l}\text { Comparison to posted speed } \\
\text { limits }\end{array}$ & \\
\hline $\begin{array}{l}\text { Extreme } \\
\text { acceleration } \\
\text { count }\end{array}$ & $\begin{array}{l}\text { Telematics accelerometer } \\
\text { or vehicle computer } \\
\text { through OBD-II }\end{array}$ & $\begin{array}{l}\text { Identify harsh cornering by } \\
\text { reading g-forces }\end{array}$ & \\
\hline $\begin{array}{l}\text { Extreme } \\
\text { braking count }\end{array}$ & $\begin{array}{l}\text { Telematics accelerometer } \\
\text { or vehicle computer } \\
\text { through OBD-II }\end{array}$ & $\begin{array}{l}\text { Determine speed reduction to } \\
\text { identify possible power } \\
\text { capture from regenerative } \\
\text { braking in hybrid and electric } \\
\text { vehicles }\end{array}$ & \\
\hline
\end{tabular}

\subsection{Idling}

Telematics can measure idling by assessing whether the vehicle is standing still while the engine is operating. Fleet managers can set idling alerts above a certain amount of time to avoid capturing stops at traffic lights or drive-through restaurants. Some devices can also monitor power take-off from external applications like a truck lift to distinguish productive idling from nonproductive idling (Geotab 2016b). Companies have also discussed monitoring ambient temperature to determine whether the air is cold or hot enough to justify idling for cab heating or cooling (Mallapragada 2016).

Reducing unnecessary engine idling is one of the easiest ways to reduce fuel consumption. Telematics systems can track these idling events and highlight the amount of fuel wasted during idling. Fuel savings from idle reductions can vary by vehicle type. Savings can approach a gallon of fuel per hour of idling in heavy-duty vehicles (Argonne National Laboratory 2017). Table 4 lists idling metrics and applications.

Table 4. Idling Metrics and Applications

\begin{tabular}{|c|c|c|c|}
\hline Data Point & $\begin{array}{l}\text { Method of Data } \\
\text { Capture }\end{array}$ & Advanced Features & $\begin{array}{l}\text { Fleet Management } \\
\text { Application }\end{array}$ \\
\hline Idling events & $\begin{array}{l}\text { Vehicle computer } \\
\text { through OBD-II }\end{array}$ & \multirow{2}{*}{$\begin{array}{l}\text { - Customize acceptable idle } \\
\text { time before triggering event } \\
\text { notification } \\
\text { - Measure idle fuel use } \\
\text { directly or estimate fuel } \\
\text { consumption based on idle } \\
\text { time }\end{array}$} & \multirow{2}{*}{$\begin{array}{l}\text { - Identify idling events and } \\
\text { review with driver } \\
\text { - Identify high idling } \\
\text { vehicles for replacement } \\
\text { with start/stop } \\
\text { technology }\end{array}$} \\
\hline $\begin{array}{l}\text { Total Idling } \\
\text { time }\end{array}$ & $\begin{array}{l}\text { Aggregated idling } \\
\text { events }\end{array}$ & & \\
\hline
\end{tabular}




\subsection{Choosing Efficient Vehicles and Reducing Vehicle Miles Traveled}

Drivers can reduce fuel consumption by choosing the most efficient vehicle meeting mission requirements and choosing the most direct or efficient route for a given trip. Telematics can support these goals by quantifying the fuel lost from inefficient decisions. Table 5 lists fleet efficiency metrics and applications.

Table 5. Fleet Efficiency Metrics and Applications

\begin{tabular}{|c|c|c|}
\hline Data Point & Method of Data Capture & $\begin{array}{l}\text { Fleet Management } \\
\text { Application }\end{array}$ \\
\hline Vehicle make and model & Fleet FMIS & $\begin{array}{l}\text { Identify larger inefficient } \\
\text { vehicles for scrutiny }\end{array}$ \\
\hline $\begin{array}{l}\text { Trip start latitude and longitude } \\
\text { Trip end latitude and longitude }\end{array}$ & AVL & Trip identification \\
\hline Trip mileage & $\begin{array}{l}\text { AVL or vehicle computer through } \\
\text { OBD-II }\end{array}$ & \multirow{2}{*}{$\begin{array}{l}\text { Compare actual to optimal trip } \\
\text { mileage to determine potential } \\
\text { avoidable VMT }\end{array}$} \\
\hline Optimal trip mileage & $\begin{array}{l}\text { Determined by navigation system } \\
\text { based on trip start and end } \\
\text { locations }\end{array}$ & \\
\hline \multirow{2}{*}{$\begin{array}{l}\text { Route/mission type } \\
\text { Geofence alert (route defined) }\end{array}$} & \multirow{2}{*}{$\begin{array}{l}\text { Manually defined based on fleet } \\
\text { manager's knowledge of the route } \\
\text { mission }\end{array}$} & $\begin{array}{l}\text { Identify trips requiring expanded } \\
\text { vehicle capabilities }\end{array}$ \\
\hline & & \multirow[b]{2}{*}{ Identify excessive VMT } \\
\hline $\begin{array}{l}\text { Geofence alert (departure from } \\
\text { installation or other expected } \\
\text { geography) }\end{array}$ & $\begin{array}{l}\text { Geofence set by fleet manager } \\
\text { and compared to AVL }\end{array}$ & \\
\hline $\begin{array}{l}\text { Geofence alert (unpaved or } \\
\text { steep terrain requiring 4-wheel } \\
\text { drive) }\end{array}$ & $\begin{array}{l}\text { Manually defined based on fleet } \\
\text { manager's knowledge of the route } \\
\text { mission }\end{array}$ & $\begin{array}{l}\text { Identify trips requiring expanded } \\
\text { vehicle capabilities }\end{array}$ \\
\hline Trip fuel consumed & Vehicle computer through OBD-II & Identify high-fuel-use trips \\
\hline $\begin{array}{l}\text { Estimated fuel consumed by } \\
\text { downsized vehicle }\end{array}$ & $\begin{array}{l}\text { Estimate calculated from trip } \\
\text { mileage and the fuel economy } \\
\text { rating of a smaller vehicle (e.g., a } \\
\text { small sedan achieving } 32 \mathrm{mpg} \text { ) }\end{array}$ & $\begin{array}{l}\text { Comparison to actual trip fuel } \\
\text { use to determine potential fuel } \\
\text { savings from using a more } \\
\text { efficient vehicle }\end{array}$ \\
\hline
\end{tabular}

\subsection{Cost Savings Associated with Driver Safety and Fleet Efficiency}

Insurance companies recognize the importance of telematics for safety, and, although the benefits of telematics are difficult to quantify, some analysts have attempted to do so.

Automotive Fleet studied accident rates in fleets with and without a safety program from 2011 to 2013. On average, $26.7 \%$ of vehicles in fleets without safety programs were involved in collisions or incidents in a given year, compared with $18.3 \%$ of vehicles in fleets with safety programs (Fletcher 2014). According to Driver's Alert, the average cost of a non-fatal accident is $\$ 16,000$ (Taylor 2014). If implementing a safety program resulted in the same annual accident frequency reduction found in the Automotive Fleet study, a generic commercial fleet would save $\$ 1,333$ per vehicle-year on average - without even considering the costs of fatal on-the-job collisions. In the federal fleet, GSA reported 7,166 collisions, 12,849 driving incidents, 621 
injuries, and 18 fatalities from government employees driving GSA vehicles in fiscal year 2014 (Schaubhut 2015). Prior to the DRIVESAFE program, 23 Marines were lost in driving incidents in a single year (U.S. Marine Corps 2011).

In 2014, the rate of collisions plus incidents $(20,015)$ as a percentage of GSA leased vehicles $(181,062)$ was $11.1 \%$. If a safety program can reduce the accident/incident rate of average fleet vehicles by $31 \%$ (as suggested by the Automotive Fleet study), then a telematics-based safety program should reduce the federal fleet accident/incident rate by the same proportion, from $11.1 \%$ to $7.6 \%$. Using the Driver's Alert accident costs $(\$ 16,000$ per accident $)$, the savings from a telematics-based safety program in the federal fleet would be about $\$ 553$ per vehicle-year, without trying to quantify the number of lives saved. Telematics might also reduce litigation costs by filming the road and driver and clearly identifying fault in a particular accident. Finally and most importantly, the Lytx Marine Corps case study references eliminating driver casualties in vehicles with telematics (Lytx 2017).

Reducing idle time, aggressive driving, and VMT also can save fleets money. Figure 10 shows an example savings analysis performed using the Alternative Fuels Data Center (AFDC) Petroleum Reduction and Planning Tool (https:/www.afdc.energy.gov/prep/\#). Here telematics monitoring and fleet management enable a hypothetical small pickup truck (the most popular non-law enforcement vehicle in the Marine Corps' fleet) to reduce idling by half, improve fuel economy by $10 \%$ through less aggressive driving, and reduce VMT by $10 \%$ (FuelEconomy.gov 2017). These measures result in $\$ 378$ of annual cost savings based on a gasoline price of $\$ 2.38$ /gallon. In addition, driving more efficiently can reduce maintenance costs through less wear on the vehicle components, particularly brakes and tires. The Organisation for Economic Co-operation and Development references estimates suggesting that telematics can help fleets reduce maintenance and repair costs by as much as 14\% (OECD 2010).

\begin{tabular}{|c|c|c|c|c|c|}
\hline Savings Methods & & $\begin{array}{l}\text { Petroleum } \\
\text { Reduction } \\
\text { gal/yr }\end{array}$ & $\begin{array}{l}\text { GHG } \\
\text { Reduction } \\
\text { tons } \mathrm{CO}_{2} / \mathrm{yr}\end{array}$ & $\begin{array}{l}\text { Fuel Cost } \\
\text { Savings } \\
\$ / y r\end{array}$ & $\begin{array}{l}\text { Impact on } \\
\text { Plan } \\
\text { percent }\end{array}$ \\
\hline Replace Vehicles & ADD TO PLAN & 0.00 & 0.00 & $\$ 0.00$ & $0 \%$ \\
\hline $\begin{array}{l}\text { Use Alternative Fuel in } \\
\text { Existing Vehicles }\end{array}$ & ADD TO PLAN & 0.00 & 0.00 & $\$ 0.00$ & $0 \%$ \\
\hline Reduce Idling & ADD ANOTHER & 60 & 1 & $\$ 143$ & $38 \%$ \\
\hline $\begin{array}{l}\text { Reduce idling in } 1 \text { small gas } \\
\text { pickup from } 2 \text { hours per day to } \\
1 \text { hour per day }\end{array}$ & $\begin{array}{l}\mathbb{2} \text { edit } \\
\otimes \text { delete }\end{array}$ & 60 & 1 & $\$ 143$ & $38 \%$ \\
\hline Reduce Mileage. & ADD ANOTHER & 52 & 1 & $\$ 123$ & $33 \%$ \\
\hline $\begin{array}{l}\text { Reduce miles traveled in } 1 \\
\text { small gas pickup from } 10,000 \\
\text { miles to } 9,000 \text { miles }\end{array}$ & $\begin{array}{l}\ll \text { edit } \\
\otimes \text { delete }\end{array}$ & 52 & 1 & $\$ 123$ & $33 \%$ \\
\hline Drive Efficiently. & ADD ANOTHER & 47 & 1 & $\$ 112$ & $30 \%$ \\
\hline $\begin{array}{l}\text { Improve efficiency in } 1 \text { small } \\
\text { gas pickup by } 10 \%\end{array}$ & $\begin{array}{l}\overline{\text { edit }} \\
\times \text { delete }\end{array}$ & 47 & 1 & $\$ 112$ & $30 \%$ \\
\hline \multicolumn{2}{|c|}{ Total savings from plan per year } & $\begin{array}{l}159 \\
\text { gallons }\end{array}$ & $\begin{array}{l}2 \\
\text { tons of } \mathrm{CO}_{2}\end{array}$ & $\$ 378$ & $100 \%$ \\
\hline
\end{tabular}

Figure 10. Single pickup truck cost savings from telematics-based efficiency program (calculated in the Petroleum Reduction and Planning Tool, https://www.afdc.energy.gov/prep/\#) 


\section{Simplifying Fleet Management}

Fleet managers can use telematics to automate time-consuming tasks for themselves and their drivers, capture more accurate data, and simplify maintenance scheduling. Fleets can use telematics to automate key aspects of their reporting requirements.

\subsection{Vehicle Utilization}

Fleet managers frequently cite mileage as the most problematic vehicle metric to collect, largely because handwritten, manual odometer readings are still a common practice in federal fleets. Similar processes are common for engine hour recording with heavy-duty vehicles or work trucks that export power to auxiliary devices (e.g., bucket trucks). Table 6 lists vehicle utilization metrics that can be captured through telematics systems and their applications.

Table 6. Vehicle Utilization Metrics and Applications

\begin{tabular}{|c|c|c|}
\hline Data Point & Method of Data Capture & Fleet Management Application \\
\hline Mileage & $\begin{array}{l}\text { Vehicle computer through OBD-II or } \\
\text { approximated by AVL after initial mileage } \\
\text { reading }\end{array}$ & \multirow{2}{*}{$\begin{array}{l}\text { - } \text { Required fleet reporting } \\
\text { - Vehicle retirement } \\
\text { - } \text { Maintenance alerts } \\
\text { - Vehicle replacement decisions }\end{array}$} \\
\hline Engine hours & $\begin{array}{l}\text { Vehicle computer through OBD-II } \\
\text { (typically only applicable to medium- and } \\
\text { heavy-duty vehicles) }\end{array}$ & \\
\hline
\end{tabular}

\subsection{Maintenance Notifications}

Fleets can further reduce fuel use and improve safety by ensuring vehicles are well maintained. Telematics can support these efforts by tracking maintenance schedules and highlighting vehicle maintenance factory alerts. Fleet managers can set alerts based on mileage (e.g., every 30,000 miles), calendar dates (e.g., annually), or whenever the check engine light is activated. By integrating the telematics readings of odometers and engine hours of operation, the systems can trigger maintenance alerts (Geotab 2016c). Table 7 lists maintenance data and applications.

Table 7. Maintenance Data and Applications

\begin{tabular}{|c|c|c|c|}
\hline Data Point & Method of Data Capture & Advanced Feature & $\begin{array}{l}\text { Fleet Management } \\
\text { Application }\end{array}$ \\
\hline DTCs & $\begin{array}{l}\text { Vehicle computer through } \\
\text { OBD-II }\end{array}$ & $\begin{array}{l}\text { DTC prioritization (e.g., } \\
\text { high priority for engine } \\
\text { overheating or low } \\
\text { priority for intermittent } \\
\text { sensor faults) }\end{array}$ & \multirow{3}{*}{$\begin{array}{l}\text { Notify fleet managers of } \\
\text { maintenance requirements }\end{array}$} \\
\hline Tire pressure & $\begin{array}{l}\text { Vehicle computer through } \\
\text { OBD-II }\end{array}$ & $\begin{array}{l}\text { Tire pressure alerts for } \\
\text { high or low pressures }\end{array}$ & \\
\hline Mileage & $\begin{array}{l}\text { Vehicle computer through } \\
\text { OBD-II or approximated by } \\
\text { AVL after initial mileage } \\
\text { reading }\end{array}$ & $\begin{array}{l}\text { Can be compared to } \\
\text { scheduled maintenance }\end{array}$ & \\
\hline
\end{tabular}




\subsection{Integration with Fleet Management Information Systems}

The FMIS is typically the crucial data reservoir for vehicle mileage, fuel use, maintenance, costs, license plates, and other vehicle attributes. It is also required by 41 CFR 102-34.347 (CFR 2008). Some FMISs, such as AssetWorks' FleetFocus, can integrate with telematics systems to capture mileage, engine hours, location, and other alerts (Orlando Barrett, AssetWorks, telephone conversation with author, July 19,2017). If properly configured, the other alerts could include DTCs, excessive speeding, and idling as configured by the fleet. In addition, fuel consumption could be captured, although it might be easier for the FMIS to capture this information through the fleet fueling credit card. In the case of FleetFocus, AssetWorks has already contracted with Verizon NetworkFleet to capture DTCs. Programming AssetWorks for another telematics provider such as WBC Fleet or Lytx DriveCam might be difficult and potentially prohibited under contractual clauses. However, mileage, engine hours, locational data, and other alerts could be arranged through collaboration among the telematics provider, the FMIS, and systems engineers.

As federal fleets transition away from aggregate-level reporting to vehicle-asset-level data, a direct data feed for FAST becomes more important. The FAST team recommends developing an XML feed from a fleet FMIS to report to FAST in order to automate that aspect of fleet reporting (Caldwell and Stewart 2016). This places a heavier emphasis on having an FMIS, which is already required by EO 13693 (White House 2015).

Agencies have options regarding how they enter data into an FMIS, and they will need to rely on multiple sources. However, telematics can report many of the key pieces of information described above, most notably mileage, engine hours as appropriate, and garage location.

\subsection{Cost Savings Associated with Simplified Fleet Management}

Maintenance-related costs include scheduling vehicles for maintenance unnecessarily, losing productivity owing to unanticipated breakdowns, and escalating problems because of undiagnosed maintenance alerts. Geotab estimates the savings potential at $\$ 20$ per month for a light-duty vehicle driving 24,000 miles per year (Geotab 2016d). For a vehicle traveling about 10,000 miles per year, the savings potential would be reduced to about $\$ 8$ per month or $\$ 99$ per year. However, when a check engine light goes unreported, it can lead to more serious problems and far more than a few dollars of lost productivity per month. Just as a spark plug that is not replaced on schedule can ruin an ignition coil, an unreported ignition coil causing a misfire can ruin an entire engine.

In addition, recording mileage and other data points like fuel consumption saves fleet managers large amounts of time, equating to reduced hourly wage expenditures or increased productivity. The time required for fleet managers to check with coordinators, coordinators to check with drivers, and drivers to track mileage with pen and paper could easily exceed an hour per month per vehicle - resulting in significant savings potential, especially from using an FMIS. Saving an hour per month per vehicle would correlate to about \$26 per month (\$312 annually) for a GS-9 employee and more for higher grades. That alone could pay for the cost of a telematics subscription at about $\$ 15$ per month. These savings relate to the number of vehicles in the fleet instead of the miles driven. 


\section{Vehicle Acquisition Support}

Beyond managing existing fleet operations, a fleet manager plans for the fleet's future. The size and composition of the fleet must change as requirements change. Telematics can support the planning process by providing data highlighting opportunities for fleet efficiency, such as alternative fuel vehicle (AFV) deployment, carpooling and shuttle programs, and right-sizing the fleet through the vehicle allocation methodology (VAM) process.

\subsection{Acquiring Alternative Fuel Vehicles}

The Energy Policy Act of 1992 requires federal fleets to acquire AFVs, while the Energy Policy Act of 2005 requires these fleets to use the alternative fuel in bi-fuel vehicles. In addition, EO 13693 requires agencies to acquire a subset of AFVs, zero-emission vehicles, and plug-in hybrid electric vehicles (PHEVs) as an increasing percentage of their passenger vehicle fleets (culminating in 50\% of acquisitions in 2025). Deploying the vehicles in appropriate locations and for missions well aligned with their capabilities can ensure the deployment is successful.

Beyond zero-emission vehicles and PHEVs, other AFV technologies can support the EO 13693 greenhouse gas emission reduction goals by using fuels with lower greenhouse gas emissions compared with gasoline. Flex fuel vehicles operate on gasoline or E85. Many CNG vehicles are bi-fuel and can run on either gasoline or CNG. Further, most diesel vehicles can operate on B20, a blend of conventional diesel with $20 \%$ biodiesel. Although all these vehicles provide flexibility, the benefits of the vehicles can only be achieved by using the alternative fuel regularly. Tracking which vehicles operate near existing alternative fuel infrastructure can help identify vehicles that could be successfully replaced by an AFV.

Alternative fuel availability can be determined based on a vehicle's garage location. Furthermore, it is required for waivers from the Energy Policy Act of $2005 \S 701$ requirement that federal bi-fuel vehicles be operated on alternative fuels (FEMP 2017). Currently, many federal fleets report only the ZIP code of the vehicle, which renders the determination of access to alternative fuel imprecise. Telematics data can report a vehicle's overnight or off-duty dwelling location for a more precise garage location. Entering this location in the AFDC Alternative Fuel Station Locator (https://www.afdc.energy.gov/locator/stations/) can determine if fuel is locally available. However, vehicles can operate far beyond the vicinity of their garage location. To complete a more comprehensive alternative fuel assessment, fleet managers can compare vehicle routes to alternative fuel station locations using applications like the AFDC Route Planner (Figure 11) or creating geofences around known local alternative fuel infrastructure. 


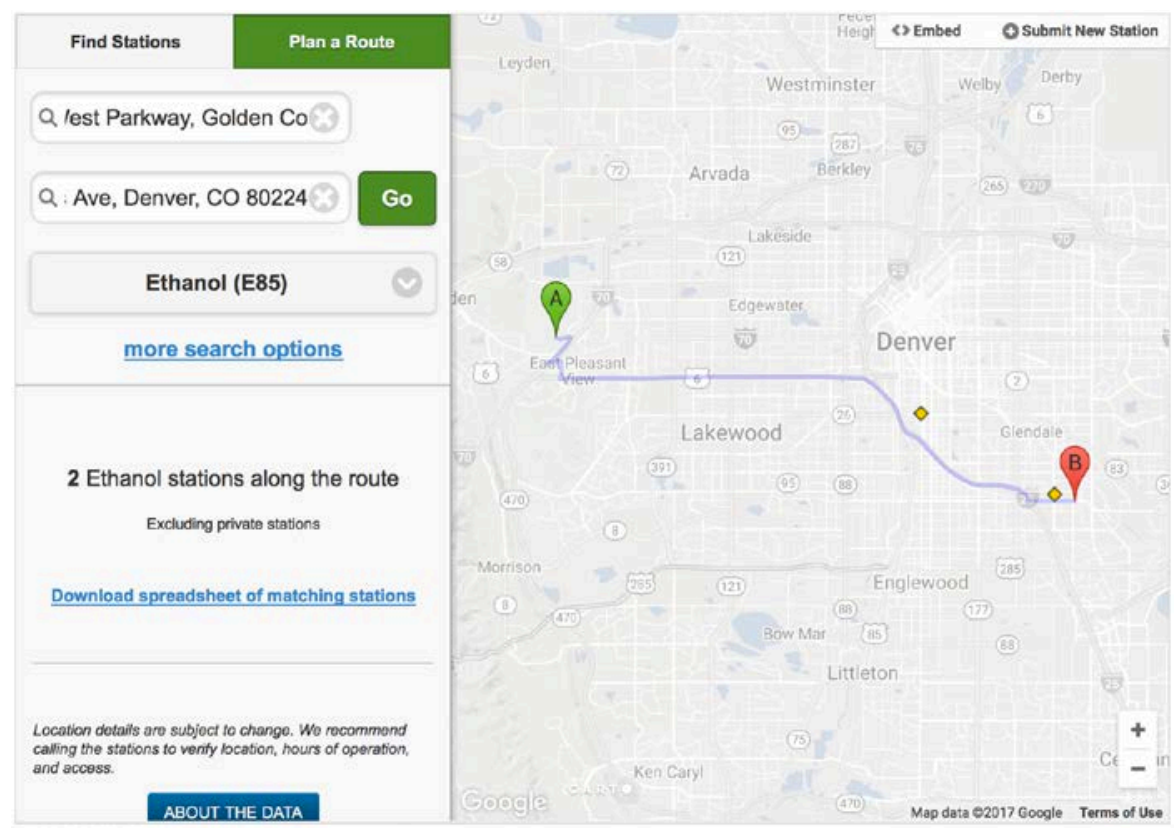

Figure 11. AFDC Route Planner

Electric vehicles are limited by battery driving range and the time required to charge the vehicles. Identifying vehicles that consistently return to a parking location where electric vehicle supply equipment is installed or could cost-effectively be installed can be accomplished by setting up geofence alerts around these parking locations. The total mileage traveled before returning to the parking location can help determine if the specific vehicle battery range would be sufficient as a replacement option. The amount of time spent in the parking location geofence can determine if there would be sufficient time to recharge the vehicle between trips.

AFVs and the infrastructure required to fuel and power the vehicles can carry significant upfront acquisition costs above the costs associated with traditional vehicles. To achieve a financial benefit by offsetting higher upfront costs with reduced fuel costs (particularly for CNG and electric vehicles), the vehicles must use a large amount of fuel. Telematics-captured mileage and fuel-use data can help identify vehicles meeting this higher threshold of use. Table 8 lists AFV suitability data and applications. 
Table 8. AFV Suitability Data and Applications

\begin{tabular}{|c|c|c|c|}
\hline Data Point & Method of Data Capture & Advanced Feature & $\begin{array}{l}\text { Fleet Management } \\
\text { Application }\end{array}$ \\
\hline Vehicle ID & $\begin{array}{l}\text { Vehicle identification number } \\
\text { capture through OBD-II or } \\
\text { manual entry }\end{array}$ & Make, model, and year & $\begin{array}{l}\text { Vehicle type and } \\
\text { suitability for AFV }\end{array}$ \\
\hline $\begin{array}{l}\text { Trip start/end } \\
\text { latitude } \\
\text { Trip start/end } \\
\text { longitude }\end{array}$ & $A \bigvee L$ & Vehicle nighttime location & \multirow[t]{2}{*}{$\begin{array}{l}\text { Primary and secondary } \\
\text { garage and destination } \\
\text { locations }\end{array}$} \\
\hline $\begin{array}{l}\text { Trip start/end } \\
\text { location ID }\end{array}$ & Geofence manual entry & $\begin{array}{l}\text { Automatic reports on } \\
\text { entry and exit }\end{array}$ & \\
\hline $\begin{array}{l}\text { Trip start/end } \\
\text { times }\end{array}$ & Telematics software & $\begin{array}{l}\text { Trip time length and time } \\
\text { between trips }\end{array}$ & \multirow{3}{*}{$\begin{array}{l}\text { Suitability for AFVs } \\
\text { (especially all-electric } \\
\text { vehicles) }\end{array}$} \\
\hline $\begin{array}{l}\text { Fuel } \\
\text { consumption }\end{array}$ & $\begin{array}{l}\text { Vehicle computer through } \\
\text { OBD-II }\end{array}$ & Fuel levels & \\
\hline Trip distance & $\begin{array}{l}\text { Vehicle odometer through } \\
\text { OBD-II or telematics AVL }\end{array}$ & $\begin{array}{l}\text { Trips aggregated by } \\
\text { day/week }\end{array}$ & \\
\hline Trip route & AVL & $\begin{array}{l}\text { Trips aggregated by } \\
\text { day/week }\end{array}$ & \multirow{2}{*}{$\begin{array}{l}\text { Alternative fuel } \\
\text { availability }\end{array}$} \\
\hline $\begin{array}{l}\text { Alternative } \\
\text { fuel station } \\
\text { location }\end{array}$ & $\begin{array}{l}\text { Geofence manual entry or } \\
\text { AFDC application } \\
\text { programming interface (API) }\end{array}$ & AFDC Route Planner & \\
\hline
\end{tabular}

\subsection{Pooling Vehicles}

Garage locations, times of operation, and overlapping routes are helpful data points for fleet managers identifying vehicles that could be pooled or combined into shuttle routes and for those managing pools or shuttles. As with AFV acquisitions, the starting point for a pooling system should be vehicle garage location. This should be expanded from the exact geolocation pinpoint provided by the telematics to a viable walking distance for the anticipated users. Most telematics systems let the fleet manager draw a geofence for whatever parking areas make the most sense in their particular case. Identifying the vehicles that park within that geofence is relatively simple; determining the geofence area requires balancing breadth of location with convenience and installation-specific considerations. Figure 12 shows example geofence shapes. 

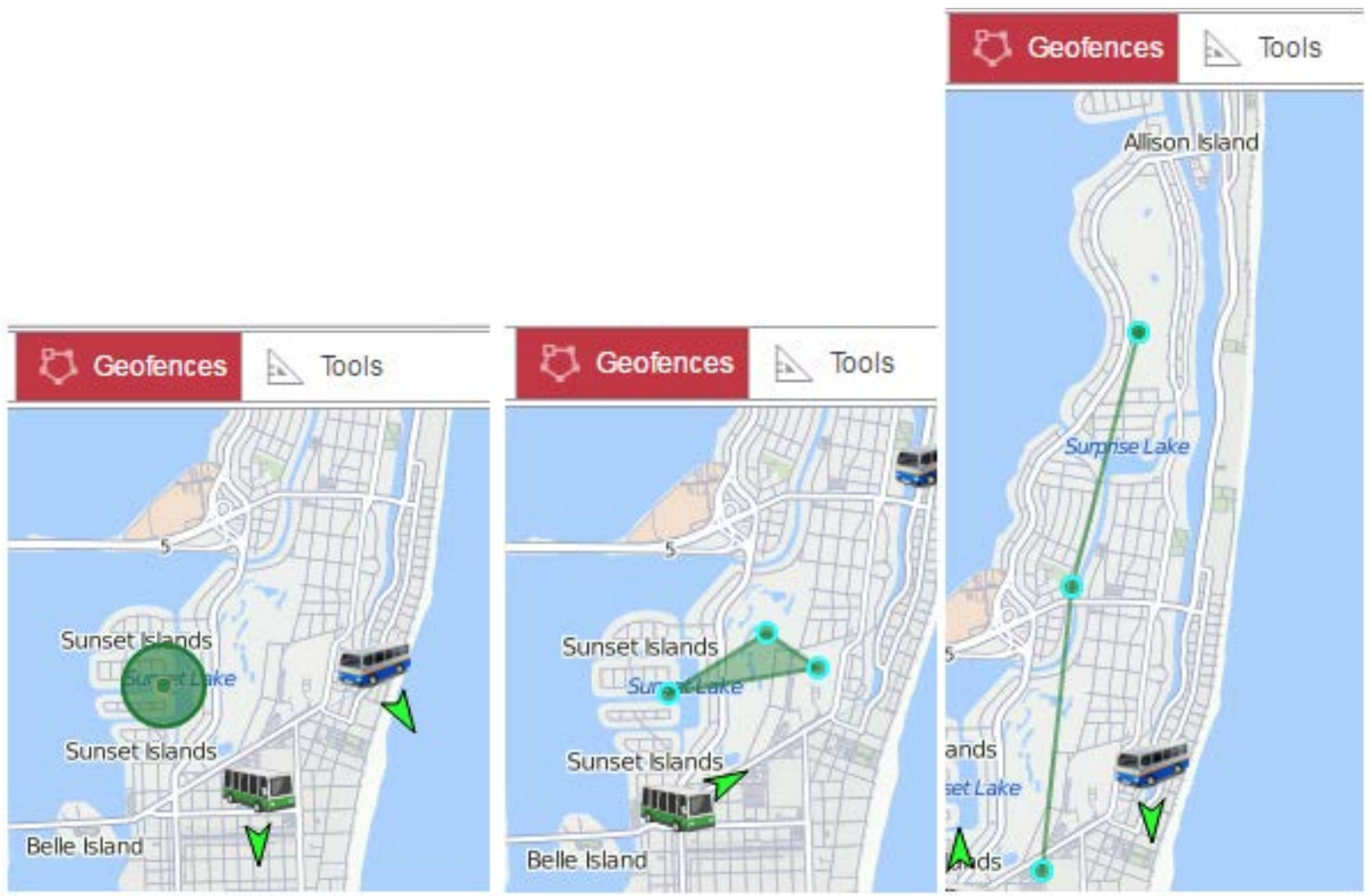

Figure 12. Geofence shapes (WBC Fleet 2017)

The second step for pooling vehicles is determining how many vehicles within the garage location geofence operate simultaneously at a peak point in time. This requires accurate, reliable trip data, which telematics systems can provide. Fleet managers can compare dwell times within geofences to see the minimum number of vehicles that remain within the geofenced area over some period, such as 30 days. This will provide the first estimate of how many vehicles could be reduced if the fleet transitioned vehicles to a motor pool.

The next step is comparing vehicle routes among the remaining vehicles. Vehicles that travel to the same destination at approximately the same time may be good candidates for carpooling within the motor pool (i.e., sharing a trip rather than alternately using the same vehicle). This can also be achieved through geofencing and strong fleet management. Fleets can map common routes using a line or a polygon and compare when vehicles are traveling to the same place at the same time. The same metrics for AFV acquisition in Table 8 are relevant to vehicle pooling, with a wider geofence to represent walkable distance between existing fleet vehicles.

\subsection{Vehicle Allocation Methodology Support}

Fleet missions evolve, and the composition of a fleet must evolve to meet the updated requirements efficiently. For this reason, EO 13693 and 41 CFR 102-34.50 require that agencies complete a structured VAM at least every 5 years to determine the appropriate size and number of vehicles (White House 2015, CFR 2011).

For example, the Marine Corps follows VAM processes to determine the requirements of each vehicle mission, whether all vehicles are necessary, and where additional or different vehicles 
may be required. Telematics can support this process by automatically collecting much of the data required in a VAM process. Although some manual effort is still likely necessary, telematics services properly deployed could significantly reduce the time and resources necessary to complete a useful VAM.

The VAM process builds on vehicle attributes, organization assignment, and mission requirement information that may already be tracked in the FMIS. Telematics systems can capture trip-level summary data that define the majority of VAM utilization rates including numbers of trips, miles traveled, hours of use, and fuel use. Existing VAM business rules defining acceptable utilization levels could highlight vehicles that could be removed or rightsized and missions that could be supplemented by additional vehicles. The resulting summaries could feed a VAM tool updated continuously without the need for an annual large-scale manual effort.

Summaries of trip counts can be created by querying trip-level data containing date and time fields. Trip count summaries can be captured as trips per year, month, week, and day. Periodic and seasonal variations can be identified by summarizing by date ranges such as:

- Date of last trip

- Months or weeks with very few or no trips

- Number of days with no trips

- Average number of trips - of the periods (month, week, day) with at least one trip

Similarly, summaries of miles traveled can be calculated including:

- Current mileage

- Previous 12 months miles

- Average miles per trip

- Average miles per week (of weeks with at least one trip)

- Average miles per day (of days with at least one trip)

Engine run-time statistics are important for medium- and heavy-duty vehicles and can be calculated, such as:

- Total hours of engine operation

- Hours per year

- Hours per trip

- Hours of the most recent day, week, month, and year

Vehicles that provide a mobile workstation, such as law-enforcement vehicles, are often in use without the engine running. Utilization statistics for these vehicles could be time away from a 
primary garage location or time at a worksite. Garage and worksite geofences could be used to determine these metrics.

Another group of utilization statistics could address fuel consumption. As with the other utilization statistics, fuel use data can be captured on a trip basis and rolled up to various periods. If the telematics system is linked with fuel transaction data, it may be possible to track the total amount of each fuel type purchased for a given period (trip, day, week, month, year, etc.). Finally, fleet managers could automatically estimate fuel savings attained by downsizing a current vehicle by comparing the current vehicle fuel consumption to the estimated fuel consumption of a more efficient vehicle traveling the same mileage.

Vehicle operating geographies can be defined through telematics systems. Known routes or areas of travel that require 4-wheel-drive capabilities (mountainous, unpaved, etc.) can be defined through geofences. Trips that enter these areas can be flagged in vehicle trip-level summaries. In this way, the number of trips requiring 4-wheel-drive capabilities can be determined for specific vehicles and summarized in a VAM report. Similarly, geofences for campus or base environments can be created. Trips can be flagged when a vehicle leaves those geographies. The VAM report could then include a count of the number of trips outside of the campus geography.

The maintenance downtime for a vehicle may also be tracked. If a geofence is created for the maintenance facility, a flag could be created each time a vehicle enters or leaves the facility. Time spent at the facility could be determined by the difference between the entrance time into and exit time out of the facility. Total maintenance downtime for a vehicle could be determined by aggregating times for individual vehicles.

Linking the telematics data to organizational hierarchies would allow the VAM report to support summaries by organizational assignment, driver usage, vehicle locations, or other important fleet grouping. These might include:

- Number of vehicles at location

- Number of individual users of the vehicle

- Number of organizations using the vehicle

The discussed metrics are not a full account of all possible telematics support for a VAM process, but they do provide a foundation for an automated VAM process. Table 9 provides a potential listing of fields and capabilities required from a telematics provider supporting a VAM. 
Table 9. VAM Data and Applications

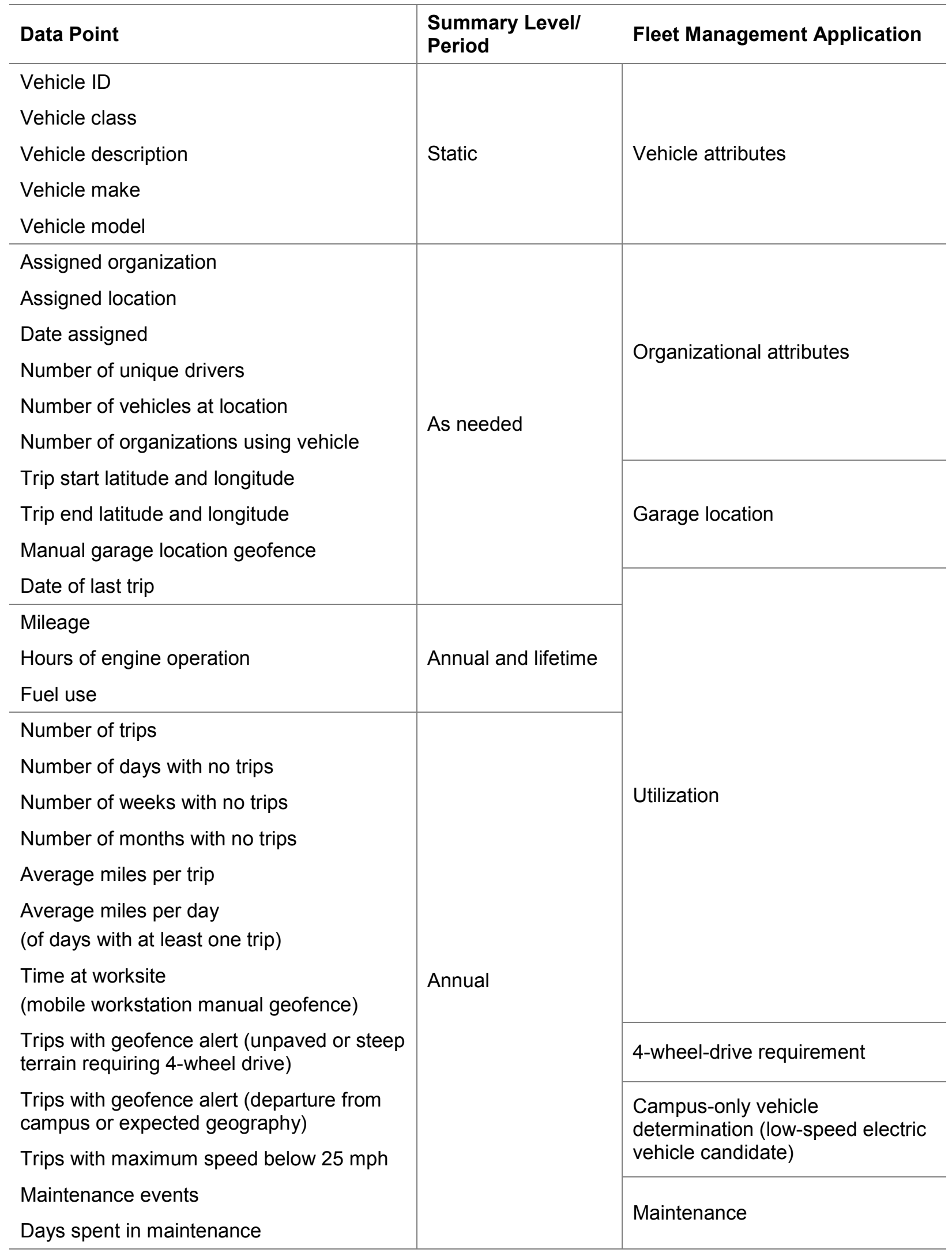


Beyond trip-level metrics, mapping capabilities of telematics services can provide quick insights to fleet planning personnel. Maps of vehicle trip traces for a chosen period including a single vehicle or across vehicles, drivers, or organizations can display where the vehicle or organization travels most regularly. Unexpected trends may stand out and highlight opportunity for additional investigation. Example events may be long-distance travel and highly repeated routes. High repetition of a single route or travel to multiple destinations in close proximity for a single vehicle or across vehicles could present an opportunity for vehicle pooling or improved route planning.

\subsection{Cost Savings Associated with Optimal Vehicle Acquisition}

Reducing the number of vehicles necessary in a fleet can result in significant savings to the federal government, which could be expressed in reduced purchases or reduced leasing costs. The example shown in Table 10 and Table 11 gives savings in terms of reduced lease costs to better pair them with the other savings expressed above. Furthermore, acquisition decisions can incorporate access to alternative fuels by comparing telematics AVL data to resources like the AFDC Station Locator (https://www.afdc.energy.gov/locator/stations/) or determining the radius of vehicle operation to determine whether an all-electric vehicle would be suitable and what range would be required (e.g., the 115-mile 2017 Ford Focus or the more expensive 238-mile Chevrolet Bolt).

In the example below, telematics can be used to determine how many vehicles could be served by a single shuttle running on a campus setting such as a military installation. Telematics data could further be entered into a VAM survey to right-size remaining vehicles, shifting toward fewer and smaller vehicles. Remaining vehicles could be pooled based on their parking proximity to one another using telematics-based geofences. The example process shown below could save the fleet $\$ 275,000$ per year by cutting the number of vehicles from 396 to 275 . Dividing the savings by the initial 396 vehicles results in a $\$ 695$ per vehicle savings.

Table 10. Optimizing a Sample Fleet via Shuttling, Right-Sizing, and Pooling (Guerra et al. 2017)

\begin{tabular}{lllll}
\hline & Now $\rightarrow$ & Shuttle $\rightarrow$ & Right-size $\rightarrow$ & Pool \\
\hline Compact sedans & 80 & 68 & 76 & 62 \\
Midsize sedans & 110 & 88 & 63 & 55 \\
Light-duty pickups & 70 & 66 & 61 & 55 \\
Light-duty sport utility vehicles & 72 & 63 & 58 & 51 \\
Light-duty minivans & 64 & 57 & 52 & 44 \\
Shuttle buses & & 8 & 8 & 8 \\
\hline Total & $\mathbf{3 9 6}$ & $\mathbf{3 5 0}$ & $\mathbf{3 1 8}$ & $\mathbf{2 7 5}$ \\
\hline
\end{tabular}


Table 11. Cost Savings from Inventory-Optimization Example

\begin{tabular}{|c|c|c|c|c|c|}
\hline Vehicle Type & $\begin{array}{l}\text { Base } \\
\text { Monthly } \\
\text { Lease Rate }\end{array}$ & $\begin{array}{l}\text { Baseline } \\
\text { Number of } \\
\text { Vehicles }\end{array}$ & $\begin{array}{l}\text { Number of Vehicles } \\
\text { after Shuttling, } \\
\text { Right-sizing, and } \\
\text { Pooling }\end{array}$ & $\begin{array}{l}\text { Monthly Cost } \\
\text { Savings }\end{array}$ & $\begin{array}{l}\text { Annual Cost } \\
\text { Savings }\end{array}$ \\
\hline Compact & $\$ 181.00$ & 80 & 62 & $\$ 3,258$ & $\$ 39,096$ \\
\hline Midsize & $\$ 222.00$ & 110 & 55 & $\$ 12,210$ & $\$ 146,520$ \\
\hline $\begin{array}{l}\text { Light-duty } \\
\text { pickup }\end{array}$ & $\$ 157.00$ & 70 & 55 & $\$ 2,355$ & $\$ 28,260$ \\
\hline $\begin{array}{l}\text { Sport utility } \\
\text { vehicle }\end{array}$ & $\$ 245.00$ & 72 & 51 & $\$ 5,145$ & $\$ 61,740$ \\
\hline Minivan & $\$ 228.00$ & 64 & 44 & $\$ 4,560$ & $\$ 54,720$ \\
\hline Shuttle bus & $\$ 575.00$ & 0 & 8 & $\$(4,600)$ & $\$(55,200)$ \\
\hline Total & & 396 & 275 & $\$ 22,928$ & $\$ 275,136$ \\
\hline
\end{tabular}

\section{Total Costs and Savings}

To calculate total savings from a telematics program, fleets can add up those savings described herein and determine which apply to them and to what degree. For example, if a fleet vehicle is leased from and maintained by GSA, the vehicle may not benefit from maintenance savings and fuel efficiency in the same cost perspective, because maintenance and fuel are included in the lease rate. However, reducing the number of vehicles will improve the bottom line, reduced fuel consumption can help agencies meet EO 13693 greenhouse gas emission goals, and any reduction in VMT will reduce the mileage rate paid in that leasing example. Similarly, although vehicles traveling in a campus setting may not benefit as much from savings due to reducing aggressive driving, they may benefit more than others from the right-sizing and shuttling capabilities. Finally, the entire federal government can benefit from safer vehicles and healthy drivers. Table 12 reviews the potential per-vehicle cost savings from a telematics program.

Table 12. Potential Per-Vehicle Cost Savings from Telematics

\begin{tabular}{ll}
\hline Measure & Annual Cost Savings \\
\hline Safety & $\$ 553$ \\
Idling & $\$ 143$ \\
Aggressive driving & $\$ 112$ \\
Reduced VMT & $\$ 123$ \\
Maintenance & $\$ 99$ \\
Reporting & $\$ 312$ \\
Inventory optimization & $\$ 695$ \\
\hline Total & $\$ 2,037$ \\
\hline
\end{tabular}

This report does not explore system pricing in detail, because it is highly dependent on the number of vehicles in a contract, the associated data plan, and system features. To look at one example, GSA offers the AT\&T Webtech system to federal fleets for $\$ 146.55$ installed in new 
vehicles with a $\$ 12$ per month data plan (Table 13). The onsite installation charge would apply to existing fleet vehicles that require a site visit.

Table 13. System Costs of AT\&T Telematics on GSA Schedule (AT\&T Fleet Management 2017)

\begin{tabular}{lll}
\hline $\begin{array}{l}\text { Aftermarket Telematics Device/Plans } \\
\text { (BPA number: GS-30F-2A051) }\end{array}$ & GPS Tracking Only & $\begin{array}{l}\text { GPS Tracking and Vehicle } \\
\text { Diagnostics }\end{array}$ \\
\hline Device (per unit) & $\$ 100.00$ & $\$ 100.00$ \\
Installation (per unit) & $\$ 46.55$ & $\$ 46.55$ \\
Data plan and web access (per month) & $\$ 10.00$ & $\$ 12.00$ \\
Total cost, year 1 & $\$ 266.55$ & $\$ 290.55$ \\
Total cost, years 2-5 & $\$ 120.00$ & $\$ 144.00$ \\
Onsite Installation (per installer/day) & $\$ 142.50$ & $\$ 142.50$
\end{tabular}

In the correct situation, telematics systems can pay for themselves easily, as demonstrated above. Although a vehicle in a campus setting may not travel far enough or fast enough to justify telematics on the basis of safety, speeding, or VMT, the systems can be used to determine which vehicles can be replaced by a shuttle, right-sized, or pooled, which can quickly repay a system that costs $\$ 290.55$ in the first year. After the fleet is downsized in this example, the telematics devices can be reassigned and repurposed.

\section{Cybersecurity Best Practices}

Fleets in general, and the U.S. military in particular, share cybersecurity concerns about the next generation of connected and automated vehicles. The concerns go beyond aftermarket telematics to all vehicle systems. Researchers at the Idaho National Laboratory were able to engage a vehicle ECU through a wiring harness to its tail lights (Rohde 2017). In several cases, OEM telematics systems have been hacked to expose the ability to take full control of the vehicle, including acceleration, steering, and braking (e.g., Valasek and Miller 2014). Remote control of the vehicle only extends to things the vehicle can do by itself. For example, a vehicle with start/stop technology can be turned on and off, a vehicle with cruise control can be accelerated, and a vehicle that can park itself can be steered (Rohde 2017).

Whether aftermarket telematics can be compromised to take control of the vehicle depends on, among other things, whether the telematics can communicate directly with the vehicle ECUs through the Controller Area Network (CAN). Most aftermarket telematics systems are designed for monitoring only. However, if the devices have a CAN-transceiver, hackers can switch on the transceiver and take control of vehicle functions by modifying the firmware (Foster et al. 2015). Foster et al. (2015) explain how to use a particular aftermarket solution to take control over vehicle brakes and other functions. In the Valasek and Miller (2014) report, the authors provide the steps necessary to replicate their work, and several other researchers have done just that.

The researchers suggest several security measures, and reviews of various telematics providers have indicated varying levels of success securing their devices (Foster et al. 2015, Valasek and Miller 2014). The Volpe National Transportation Systems Center developed the "Telematics Cybersecurity Primer for Federal Agencies" (Volpe 2017), which identifies several security 
measures for telematics systems. Volpe recommends a layered approach to cybersecurity, including applying the principles of least privilege and least functionality, authentication and authorization measures, penetration testing and event auditing, and several other preventive and responsive measures. In a presentation from the Volpe Center, Kevin Harnett specifically identified key measures, such as secure over-the-air updates, a firewall, an intrusion-prevention system to blacklist known threats, an intrusion-detection system to notify system managers about possible attacks, a secure central gateway, and a hardware security module, which would include safeguards for digital keys and cryptographic processing (Harnett et al. 2015). Similarly, Foster et al. (2015) recommend using update authentication, Short Message Service (SMS) authentication, digital key management, and password management as well as disabling wide area network (WAN) administration and maintaining an updated system server.

More generally speaking, fleet managers should work with their information technology teams to determine the level of the threat and conduct a risk-management assessment. The U.S. Navy is currently developing a risk-management framework (RMF) for its vehicle telematics to implement security controls and ensure safe operation of the systems in their vehicles. Figure 13 depicts a general overview of the RMF process.

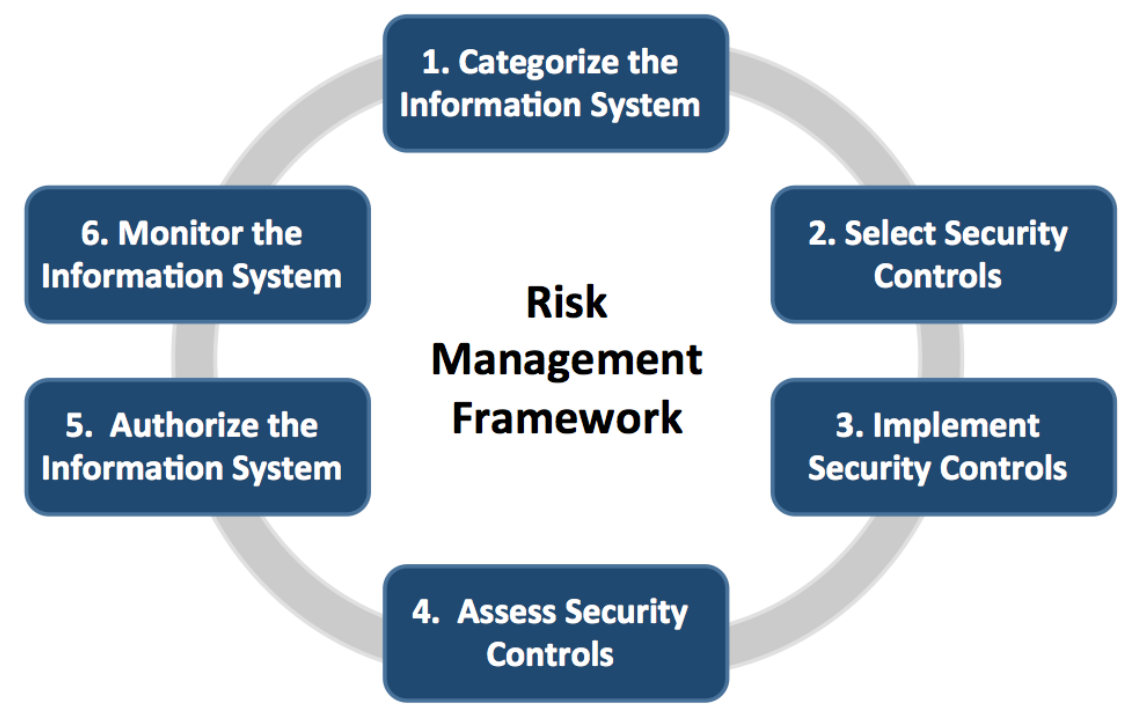

Figure 13. Risk-management framework overview (NAVFAC 2017)

The Department of Homeland Security (DHS) has completed its own cybersecurity evaluation process, including testing telematics devices to ensure they are secure. DHS's request for quotation includes several security requirements, including standards and protocols for encryption, firmware signature, asset management, vulnerability management, configuration management, malware management, log retention, identification verification, patch management, ongoing tests, and near-real-time security status information to the agency (DHS 2016).

Geotab is working with DHS to develop a System Security Plan that describes the security controls that should be implemented in telematics systems in deeper detail (Geotab 2017d). Once published, the document is intended to provide a platform-neutral guide for telematics companies and users on cybersecurity policies, procedures, and practices. 
The Federal Risk and Authorization Management Program (FedRAMP) provides a process for federal agencies to conduct a risk-management assessment on a government-wide basis with cloud service providers, such as telematics companies. FedRAMP follows procedures from the National Institute of Standards and Technology to comply with federal requirements (NIST 2017). Through FedRAMP, telematics providers can become certified to work with any federal agency. For more information, visit https://www.fedramp.gov/about-us/about/.

\section{Conclusion and Recommendations}

Telematics systems help improve safety, efficiency, and fleet management, as shown by many commercial fleets and the experience of the Marine Corps. Federal fleets can learn from the Marine Corps' success, especially in support of driver safety. As telematics data and system capabilities continue to evolve and expand, federal fleets will benefit most from these capabilities by clearly defining goals for their telematics programs.

Below is a summary of recommendations derived from this report that can help fleet managers get the most productivity and cost savings out of their systems while promoting driver safety.

1. Create a Safety Goal and Accountability System: The Marine Corps defined a clear goal of improving driver safety with top-to-bottom support from the fleet management chain of command and operational supervisors. It then deployed telematics to support this goal and prioritized fleet management and unit commanders engaging their drivers. Other fleets should follow this example and implement safety programs using telematics.

2. Build Fleet Efficiency Reporting Toolsets: Fleets can develop reporting capabilities to support efficient driving behaviors such as reducing inefficient driving, reducing idling, reducing unnecessary VMT, and choosing efficient vehicles for missions. A good starting point could be tracking idling events that exceed 5 minutes, speeding that exceeds 10 $\mathrm{mph}$ above the posted limit, and identifying the poor and strong performers measured by fuel use metrics provided by a telematics solution.

3. Automate Data Capture for Key Metrics: Fleets can plan to coordinate with internal FMIS teams and telematics providers to integrate the collection of important regulatory tracking metrics such as mileage and fuel consumption. Many telematics providers have APIs that allow telematics data to be integrated with the internal FMIS.

4. Develop Maintenance Alerts: Fleets can configure maintenance alerts based on miles traveled and DTC alerts. These alerts can be set to email codes to the fleet manager, drivers, and in-house technicians any time a check engine light turns on. In addition, they can be used to schedule routine maintenance, from oil changes to timing belts, based on manufacturer-recommended timetables.

5. Use Geofences to Identify Vehicle Operating and Parking Geographies: Fleet managers can set geofences to evaluate fleet operating geographies. Vehicle trip start and stop locations can help identify vehicle garage locations and remove the manual effort of drivers reporting it themselves. Analyzing the trips of the vehicles consistently returning to geofenced parking areas will allow fleets to determine whether vehicles can be pooled or if a shuttle is an appropriate way to combine trips. Installation- or campus-setting geofences can help identify which vehicles travel only onsite and which need to drive 
farther. Geofences around well-defined routes can be used to trigger alerts when drivers travel beyond where they should be operating. Finally, geofences around areas that require off-road capabilities can help determine whether vehicles travel to these locations regularly and help justify the need for the expanded capability.

6. Use Telematics in Support of the VAM: Fleet managers can require telematics systems to collect data needed to complete the VAM, which will reduce manual efforts and increase accuracy. Telematics can collect vehicle utilization statistics including summaries of trips, mileage, engine run-time, and fuel use. Vehicle trip data can be incorporated, such as trip times and trip geographies including primary garage location, trip start and stop locations, and geofence alerts. Feeding these metrics into the existing VAM process can reduce manual efforts.

7. Use Telematics in Support of Vehicle Acquisitions: Fleets can use telematics data during the vehicle-acquisition process, especially if they collect geofence and VAM information as described in recommendations 5 and 6 . Initial considerations should rely on readily available metrics. Those fleet locations with alternative fuel infrastructure can target vehicles of the appropriate alternative fuel type. Vehicles that consistently return to a regular parking spot and do not travel more than a plug-in electric vehicle battery range in a single day can be targeted for plug-in electric vehicle replacement. Low-mileage vehicles that do not leave an installation or campus geofence can be considered for replacement by a low-speed electric vehicle or combined into a shuttle route. Vehicles rarely entering an off-road geofence can be replaced by smaller vehicles that are not allwheel drive. Vehicles parked in the same area that do not operate at the same time can be combined into motor pools.

8. Review Cybersecurity Issues before Acquiring Telematics: Fleet managers do not need to become cybersecurity experts, but they should consult such experts when choosing a telematics provider. Often, an agency's own information technology team can help determine which issues to prioritize. Existing resources like FedRAMP and the Volpe Center's Cyber Security Primer — and experienced agencies like DHS — can be key assets in developing cyber risk mitigation strategies. 


\section{References}

AFDC (Alternative Fuels Data Center). 2017. "Efficient Driving Behaviors to Conserve Fuel." Accessed August 2017. https://www.afdc.energy.gov/conserve/driving behavior.html

Argonne National Laboratory. 2017. "Vehicle Idle Reduction Savings Worksheet." Accessed August 10, 2017. http://www.anl.gov/energy-systems/downloads/vehicle-idle-reduction-savingsworksheet

AT\&T Fleet Management. 2017. “The Driving Force.” Presented at INTERFUEL, February 8, 2017.

Automotive Fleet. 2016. "Maintenance, Safety, and Compliance Aided by Telematics." Automotive Fleet, November. http://www.automotive-fleet.com/channel/gps-

telematics/article/story/2016/11/maintenance-safety-and-compliance-why-telematics-should-beyour-sidekick.aspx

Automotive Fleet. 2015. "Verizon NetworkFleet: Cutting Fuel Costs." Automotive Fleet, January. http://www.automotive-fleet.com/channel/gps-telematics/video/detail/2015/01/verizonnetworkfleet-cutting-fuel-costs.aspx

CalAmp. 2017. “GPS Tracking Unit with OBD-II Interface.” Accessed September 2017. http://www.calamp.com/products/tracking-and-telemetry-devices/fleet-tracking-units/lmu-3030

Caldwell, J., and R. Stewart. 2016. "Federal Automotive Statistical Tool (FAST): Preparing for Vehicle-level Data Reporting." Presented at Energy Exchange, August 10, 2016. http://www.2017energyexchange.com/demo/wp-content/tracks/track14/T14S4_CaldwellStewart.pdf

car2go. 2012. “Introducing EcoScore!” car2go Insights, May 25. https://blog.car2go.com/2012/05/25/new-car2go-feature-ecoscore/

CFR (Code of Federal Regulations). 2011. 41 CFR 102-34.50. https://www.gpo.gov/fdsys/pkg/CFR-2011-title41-vol3/pdf/CFR-2011-title41-vol3-sec102-34$\underline{50 . p d f}$

CFR (Code of Federal Regulations). 2008. 41 CFR 102-34.347. https://www.gpo.gov/fdsys/pkg/CFR-2008-title41-vol3/pdf/CFR-2008-title41-vol3-sec102-34$\underline{347 . p d f}$

DataOne Software. 2016. "Infotainment vs. Telematics Systems: What is the Difference?" VIN Basics Blog, April 21. https://vin.dataonesoftware.com/vin basics blog/vehicle-infotainment-vstelematics-systems-what-is-the-difference

Department of the Navy. 2011. Marine Corps Order 5100.19F. November 29. http://www.mcieast.marines.mil/Portals/33/Documents/Safety/Orders\%20and\%20Pubs/Orders \% 20and $\% 20$ Directives/MCO $\% 205100.19 \mathrm{~F} \% 20$ Marine $\% 20$ Corps $\% 20$ Traffic $\% 20$ Safety $\% 20$ Progr am\%20DRIVESAFE.pdf 
DHS (U.S. Department of Homeland Security). 2016. DHS Request for Quotation HSHQDC-17Q-00002 - Vehicle Telematics, December 29. Washington, DC: DHS.

FEMP (Federal Energy Management Program). 2017. "Federal Fleet Management Requirements." Accessed August 2017. https://energy.gov/eere/femp/federal-fleet-managementrequirements

Fletcher, L. 2014. “Accident Management Costs Rise 6.2 Percent.” Automotive Fleet, September. http://www.automotive-fleet.com/article/story/2014/09/2014-accident-management-costs-on-the$\underline{\text { rise.aspx }}$

Foster, I., A. Prudhomme, K. Koscher, and S. Savage. 2015. "Fast and Vulnerable: A Story of Telematics Failures." Presented at the $9^{\text {th }}$ USENIX Workshop on Offensive Technologies, August 10, 2015. https://www.usenix.org/system/files/conference/woot15/woot15-paperfoster.pdf

FuelEconomy.gov. 2017. "Driving More Efficiently.” Accessed August 10, 2017. https://www.fueleconomy.gov/feg/driveHabits.jsp

Geotab. 2017a. "Product Guide." Accessed 2017. https://www.geotab.com/productguide/\#kix.531f0yiffp1i

Geotab. 2017b. "Geotab GO7—Expandable Plug-\&-Play Telematics Device.” Accessed August 2017.

https://docs.google.com/document/d/1rOJZzzZhoKXWrmswaseUr3Wk8h_nPXPK4yFtdi6yVJ0/ $\underline{\text { edit }}$

Geotab. 2017c. "GPS Fleet Management Solutions." Accessed August 2017. https://www.geotab.com/fleet-management-solutions/

Geotab. 2017d. Geotab Telematics Platform: System Security Plan, Version 0.5. Draft report, September 14. Oakville, ON, Canada: Geotab.

Geotab. 2016a. "What is G-Force?" Geotab Blog, December 14. https://www.geotab.com/blog/what-is-g-force/

Geotab. 2016b. "How to Detect and Stop True Fleet Idling." Geotab Blog, June 17. https://www.geotab.com/blog/detect-stop-true-fleet-idling/

Geotab. 2016c. "Quick Guide to Preventative Maintenance Planning for Fleets." Geotab Blog, January 27. https://www.geotab.com/blog/preventative-maintenance-planning-for-fleets/

Geotab. 2016d. "Increasing Fleet Profitability with Telematics." Geotab Blog, June. https://www.geotab.com/fleet-profitability-coi-roi/

Geotab. 2014. "Understanding Your Vehicle Odometer." Geotab Blog, March 27. https://www.geotab.com/blog/understanding-vehicle-odometer/ 
Gorman, C. 2017. "Why Automakers Should Support Aftermarket Telematics.” Accessed August 10, 2017. http://www.nastf.org/files/public/Presentations/NASTF130308Telematics.pdf

Gough, J. 2017. "Leveraging Telematics: Marine Corps Edition.” Presented at Energy Exchange, August 15, 2017. http://www.2017energyexchange.com/wp-content/uploads/T7S3 Gough.pdf

GSA (U.S. General Services Administration). 2017. "GSA Fleet Minimum Vehicle Replacement Standards.” Accessed June 8, 2017. www.gsa.gov/portal/getMediaData?mediaId=218887

Guerra, K., S. Gresalfi, and J. Bentley. 2017. "Federal Fleet Management: Fleet Laws and Regulations." Presented at Energy Exchange, August 15, 2017.

http:/www.2017energyexchange.com/wp-content/uploads/T7S1 Guerra Gresalfi Bentley.pdf

Harnett, K., G. Watson, and B. Harris. 2015. "Summary of Recent Vehicle Cybersecurity Attacks/Vulnerability Research and State-of-the-Art Mitigations Applicable to Government Vehicles." Presented at the Annual Computer Security Applications Conference, December 10, 2015.

https://www.acsac.org/2015/program/ACSAC $\% 202015 \% 20$ Vehicle $\% 20$ Cybersecurity $\% 20$ \%20Volpe.pdf

Lytx. 2017. "Client Success: United States Marine Corps Case Study.” Accessed September 2017. https://www.lytx.com/en-us/client-success/usmc\#case-study-read

Lytx. 2014. Case Study: United States Marine Corps. San Diego: Lytx. http://info.drivecam.com/rs/lytx/images/Lytx-CaseStudy-USMarineCorps-010220.pdf

Mallapragada, P.J. 2016 "Diesel Savings To Be Had via Smarter Idling.” JOC, September 13. http:/www.joc.com/trucking-logistics/trucking-equipment/truckers-can-save-big-basing-idlingrequirements-ambient-temperature 20160913.html

National Safety Council. 2017. “Cell Phone Distracted Driving.” Accessed August 2017. http://www.nsc.org/learn/NSC-Initiatives/Pages/distracted-driving-problem-of-cell-phonedistracted-driving.aspx.

NAVFAC (Naval Facilities Engineering Command). 2017. "NAVFAC Risk Management Framework: A Team Informational Brief.” Internal presentation, April 10, 2017.

NIST (National Institute of Standards and Technology). 2017. "NIST Special Publication 80053.” Accessed August 2017. https://nvd.nist.gov/800-53

OECD (Organisation for Economic Co-operation and Development). 2010. "Toward Smarter Supply Chains." OECD Observer, May. http://m.oecdobserver.org/news/fullstory.php/aid/3275/Towards smarter supply chains.html

PEGASAT. 2017. "CP1 - 1080P Vehicle Incident Camera." http://www.pegasat.net/product-p/cp1-1080p.htm 
PS Market Research. 2016. Global Telematics Market Size, Share, Development, Growth and Demand Forecast to 2022. New York: PS Market Research.

https://www.psmarketresearch.com/market-analysis/global-telematics-market

Rohde, K. 2017. "Electric Vehicle Cyber Research." Presented at Energy Exchange, August 16, 2017. http://www.2017energyexchange.com/wp-content/uploads/T7S6 Rohde.pdf

Sawatch Group. 2017. Electric Vehicle Suitability Analysis: Prepared for the University of Connecticut. NREL/SR-5400-69018. Golden, CO: National Renewable Energy Laboratory.

Schaubhut, G. 2015. "Safety and Accidents When Leasing from GSA." Presented at the 2015 General Services Administration Federal Fleet Management Training. https://www.gsa.gov/portal/getMediaData?mediaId=209015

Stewart, M. 2016. “Aftermarket vs. In-Market: OEM Telematics vs. Verizon Hum.” Motor Trend, July 1. http://www.motortrend.com/news/aftermarket-vs-market-oem-telematics-vsverizon-hum/

Taylor, V. 2014. “Attention Fleet Manager: Fleet Safety is Important Too!” Driver's Alert, October 13. https://www.driversalert.com/attention-fleet-manager-fleet-safety-is-important-too/

Telogis. 2014. "Harsh Braking and Acceleration - Why Monitor?" Telogis Blog, July 30. https://www.telogis.com/blog/harsh-braking-acceleration-why-monitor.

U.S. Marine Corps. 2011. "Marine Corps Safe Driving Program and Requirements." October. http://www.safety.marines.mil/Portals/92/Docs/DYK\%20OCT\%202011\%20Driving\%20Require ments.pdf

Valasek, C., and C. Miller. 2014. "Adventures in Automotive Networks and Control Units." IOActive Technical White Paper.

https://ioactive.com/pdfs/IOActive_Adventures_in_Automotive_Networks_and_Control_Units.p df

Verizon. 2016. "Use Engine Diagnostics to Cut Costs and Maintain Your Fleet." eBrief, January 22. http://info.networkfleet.com/rs/networkfleet/images/WP-N032_Diagnostics.pdf

Viasat. 2017. "GPS Tracking of Fuel Consumption Using the Factory-Installed Fuel Sensors." January 4. http://www.viasattech.com/en/blog/gps-tracking-of-fuel-consumption-using-thefactory-installed-sensor-of-the-vehicle

Volpe (Volpe National Transportation Systems Center). 2017. Telematics Cybersecurity Primer for Federal Agencies. Draft report, June 27, 2017. Cambridge, MA: Volpe.

Wagencontrol. 2015. "Fuel Telematics Explained: Main Tasks within GPS Tracking Solution + Infographics." Wagencontrol Blog, December 14. http://wagencontrol.eu/fuel-telematicsexplained-main-tasks/ 
Wahlstrom, J., and I. Skog. 2016. "Smartphone-based Vehicle Telematics: A Ten-Year Anniversary." IEEE Transactions on Intelligent Transportation Systems PP(99): 1-24.

WBC Fleet. 2017. “Content Management Guide: Geofences.” Accessed August 2017. http://www.wbcfleet.com/info/geofences

White House. 2015. Executive Order -- Planning for Federal Sustainability in the Next Decade. March 19. https://obamawhitehouse.archives.gov/the-press-office/2015/03/19/executive-orderplanning-federal-sustainability-next-decade 


\section{Appendix A: Telematics Providers in the Federal Fleet}

Within the telematics industry, features vary across providers. The industry itself is extremely large, totaling \$25.3 billion in revenue and projected to grow to \$140.1 billion in 2022 (PS Market Research 2016). Telematics systems enable connected vehicles, they are key to developing autonomous vehicles, and they offer big data solutions in the government and private sectors. Although the market is large with dozens of quality providers, this report focuses on the telematics systems currently used by federal fleets, such as the Marine Corps.

The descriptions below illustrate the variety of features available to fleets and do not necessarily reflect capabilities in any particular agency's telematics solution, nor do they represent endorsements by NREL or the U.S. Department of Energy.

\section{Lytx DriveCam}

Lytx (www.lytx.com) has focused on vehicle and driver safety in its DriveCam package of services. The system is built around the tracking of specific events associated with unsafe driving. When these events occur, they are recorded, and the video footage is made available for behavior coaching.

Trigger events include speeding, aggressive braking and cornering, following at an unsafe distance, unsafe lane changing, and failing to stop appropriately. Unsafe driver behaviors such as cellular phone use, eating or drinking, not using a seat belt, and drowsy driving are also tracked.

Many of these driving behaviors also affect fuel consumption, and Lytx has developed capabilities to monitor fuel savings opportunities from inefficient driving habits. These events include:

- Idling

- Excessive accelerations

- Excessive throttle increases

- Excessive revolutions per minute (RPM) increases

- Speeding

- Hard cornering

- Hard braking

These events are captured through a combination of the OBD-II port, accelerometer measurements, and GPS equipment. Mileage and fuel consumption data are available through the OBD-II for roughly $90 \%$ of vehicles from 2008 or later that use OBD-II reporting standards. Fuel consumption while idling is directly measured and is a primary efficiency opportunity.

Lytx has developed a proprietary fuel score created by tracking these events and summarizing them in a single value by driver or vehicle. In addition, Lytx has created fuel saved or lost values based on a proprietary algorithm that estimates the impact on fuel consumption of the driving metrics above. Vehicles can be compared against other vehicles or drivers in the fleet as well as 
among all Lytx customers on any one of the specific metrics, the fuel score, or the fuel saved or lost values. These comparisons allow Lytx to highlight efficient drivers and those with room for improvement.

The Lytx GPS capabilities allow for live tracking of assets. The tool allows operational management to see if vehicles are operating where and when they should be. The map interface Lytx provides identifies specific locations of vehicles as well as the route history for each vehicle (Figure A - 1). The locations of a range of events captured by the event recorder can be identified including speeding, idling, short following distances, and unsafe lane departures. The GPS view also allows for the creation of geofences and alerts for when vehicles enter or leave these areas.

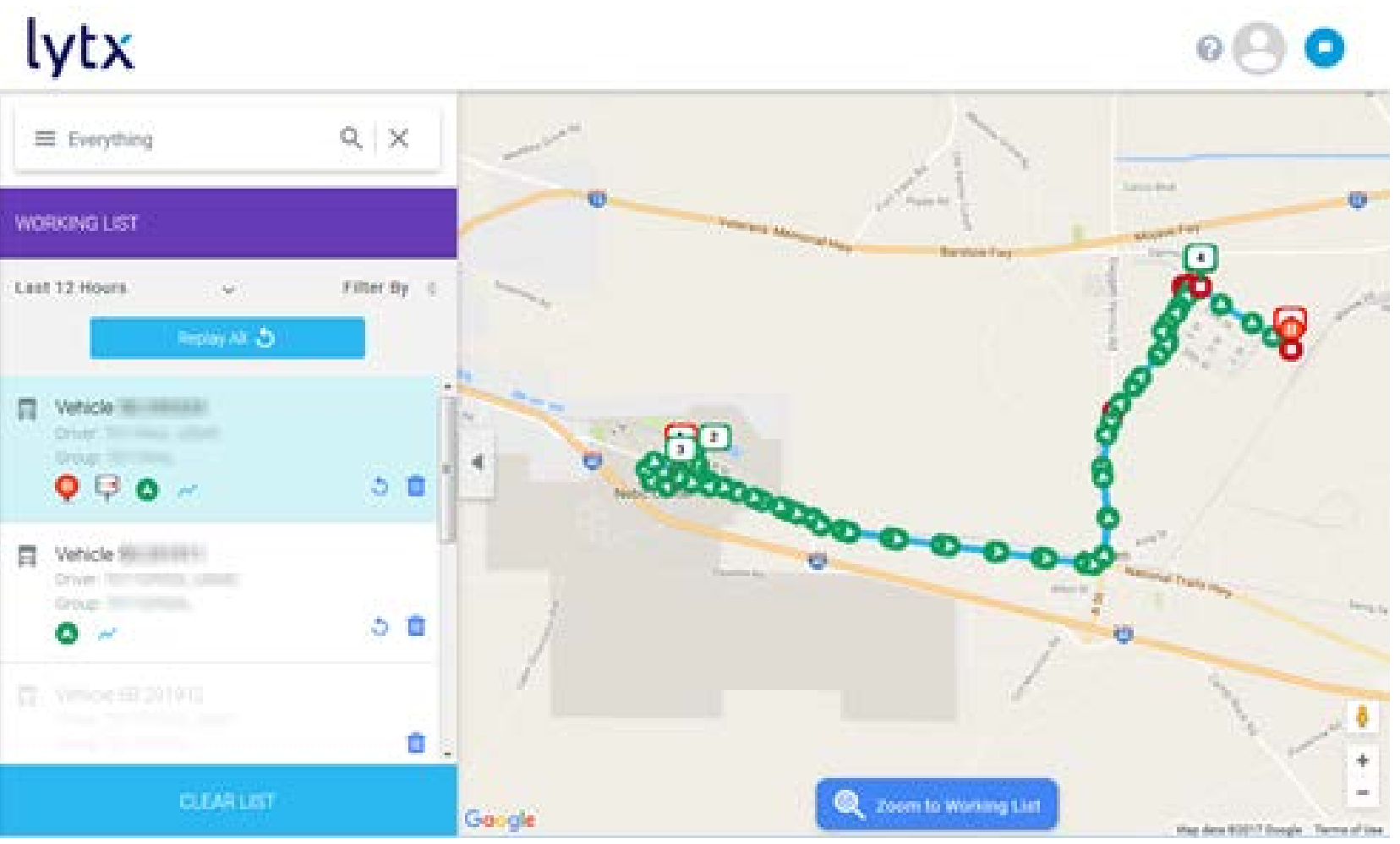

Figure A - 1. Lytx fleet tracking interface

Lytx's DOL tool displays safety event listings, allows users to access specific safety event information, and gives access to the accompanying video (Figure A - 2). Users can navigate to summaries of events by specific drivers, vehicles, and telematics equipment units. The tool also allows supervisors to log coaching efforts with drivers, enabling tracking of the effectiveness of coaching. 


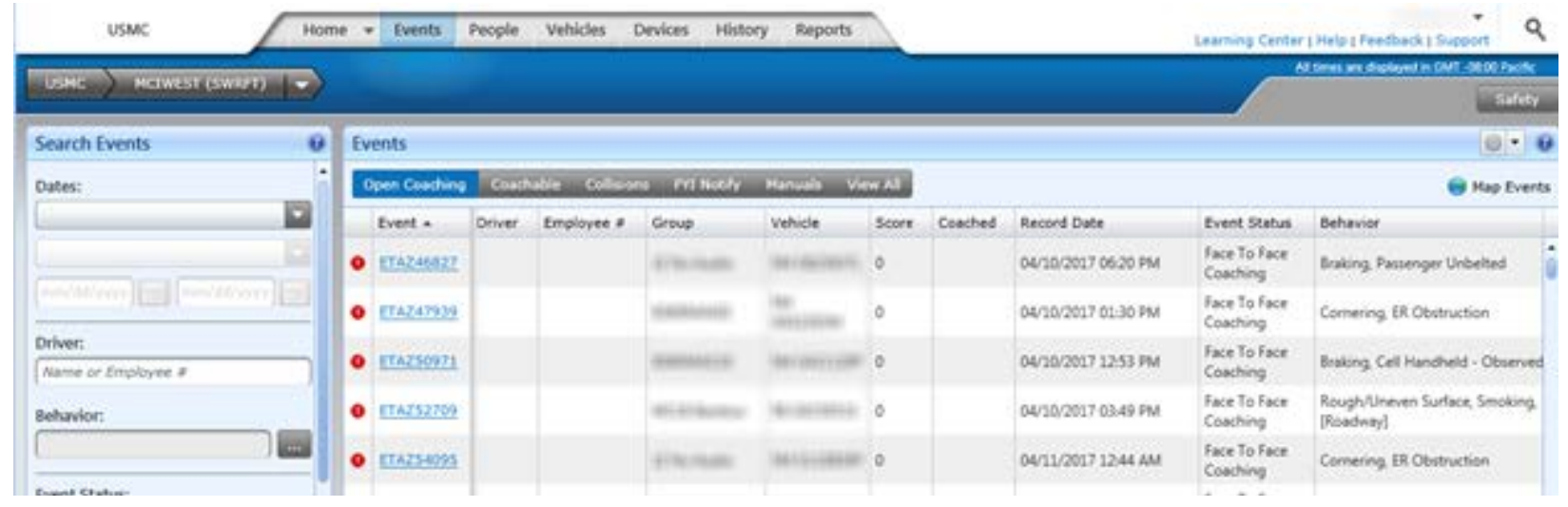

Figure A - 2. DriveCam Online interface

In addition to the safety event logs, users can access summary reports in the DOL tool. Specific idling reports as well as detailed fuel use reports are available. These fuel use reports include records at the trip level that detail the vehicle odometer reading at the beginning and end of each trip along with the inefficient driving behavior metrics mentioned previously (Figure A - 3).

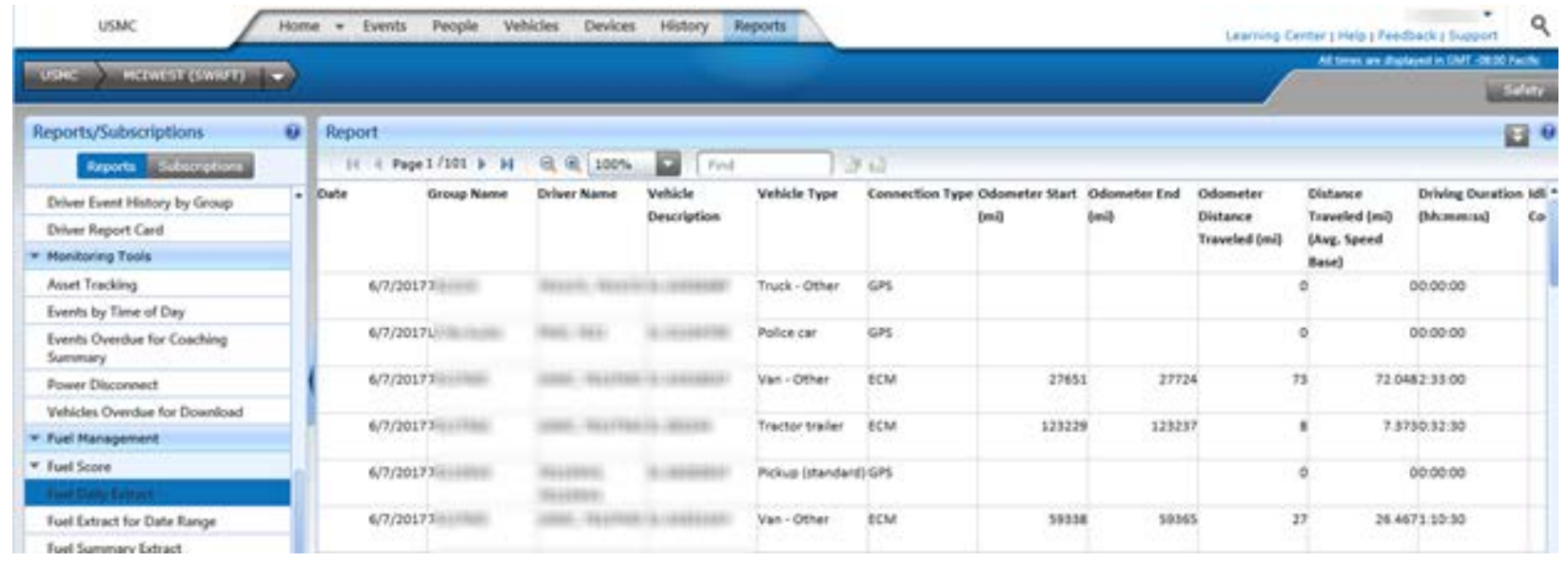

Figure A - 3. Fuel daily extract interface

In addition to the reporting capabilities available directly in the tool, Lytx provides for customizable Excel reports that can be downloaded from the tool by users with appropriate permissions or created offline by Lytx and emailed directly to users.

Lytx has also developed APIs to interface with fleet internal systems or third-party service providers. The APIs can support integration with third-party efforts such as vehicle maintenance programs, navigation systems, or driver dispatch systems. In addition, the APIs can be used to connect to a fleet's FMIS. The process of connecting the Lytx data with an FMIS involves fleet management decisions about what data to capture as well as the manual effort of the fleet's internal information services support team to write code to access the API and populate the FMIS.

Lytx uses a number of cybersecurity protections. The Lytx event recorder connection to the OBD-II port is not currently able to send messages to the vehicle CAN. Firmware on the event recorder is updated over the air, and the update packages contain a 4,096-bit key. The Lytx devices use Transport Layer Security/Secure Sockets Layer (TLS/SSL) encrypted connections to 
transfer information. Each unit has its own international mobile equipment identity (IMEI) number, and the network verifies the IMEI to prevent spoofing. The Lytx online application is firewall protected, and Lytx has a disaster recovery facility as well as offsite backups.

\section{WBC Fleet}

WBC Fleet uses CalAmp hardware to connect to the OBD-II and provide traditional telematics services, such as performance analysis, mileage tracking, and fuel consumption tracking (Figure A - 4). Because it does not use a video monitor, it cannot observe the drivers themselves, only the vehicle operation. WBC Fleet tracks unsafe behavior such as speeding as well as vehicle efficiency, including an eco-driving analysis and reports that can be summarized by fleet division.

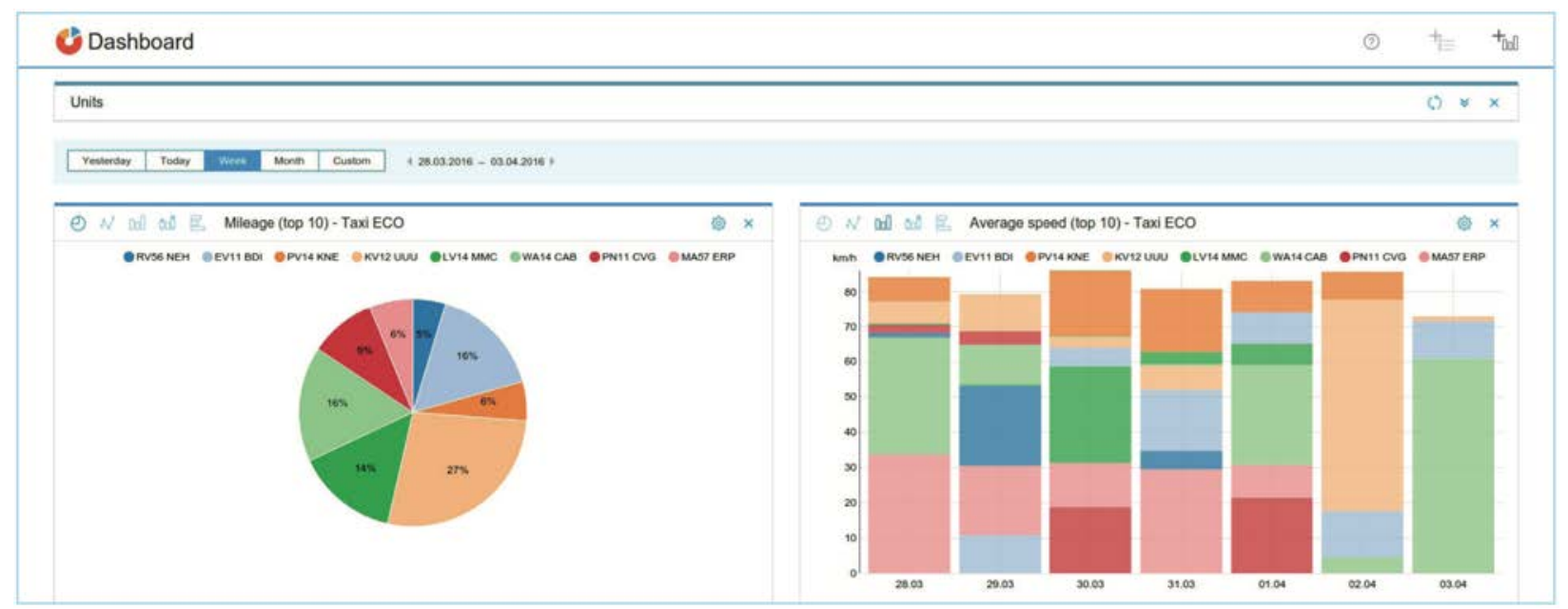

Figure A - 4. WBC Fleet mileage and average speed dashboards

WBC Fleet can connect to a vehicle through the OBD-II dongle using several types of devices, including the CalAmp LMU-303x (CalAmp 2017, Figure A - 5). CalAmp can integrate with Magellan or Garmin to provide driver GPS devices as well. In addition, WBC Fleet can integrate with camera equipment made by various manufacturers, such as the Smart Witness GP-1 (Pegastat 2017, Figure A - 6).

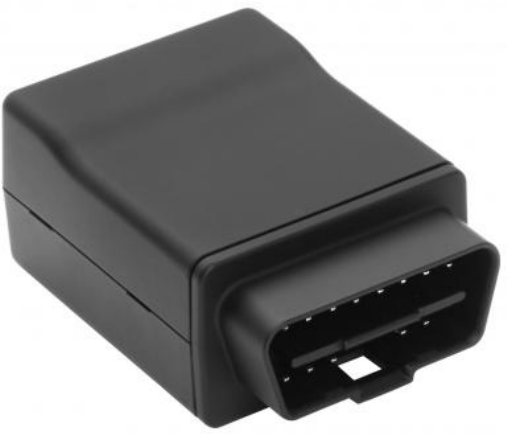

Figure A - 5. CalAmp LMU-303x

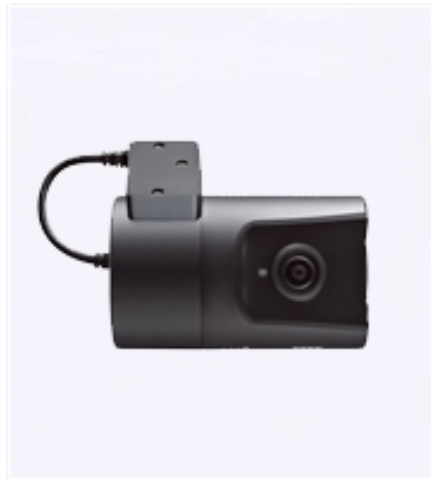

Figure A - 6. Smart Witness GP-1 
WBC Fleet can record mileage, fuel consumption, and fuel levels from the vast majority of post1996 vehicles, although it may not be able to in some vehicle models, particularly older ones. In addition, vehicle modifications such as a wheelchair lift may interfere with the operation of any devices installed in OBD-II ports. Users can capture approximate VMT readings despite such interference, if an accurate starting mileage is entered in the WBC Fleet portal.

WBC Fleet can integrate with an FMIS and has done so with fuel service systems and truck asset tracking. The company has developed an API that could be integrated with an external system, although the process would involve decisions about what data to capture and how it should appear as well as the manual effort to write the code.

WBC Fleet devices provide GPS tracking and geofencing services for the fleet manager (Figure A - 7). This can be particularly informative in a vehicle pooling situation. Taken together with the mileage and fuel data, the pooled vehicles could automatically report when they return to base, how many miles they drove, where they drove those miles, and whether they will need fuel before the next trip.

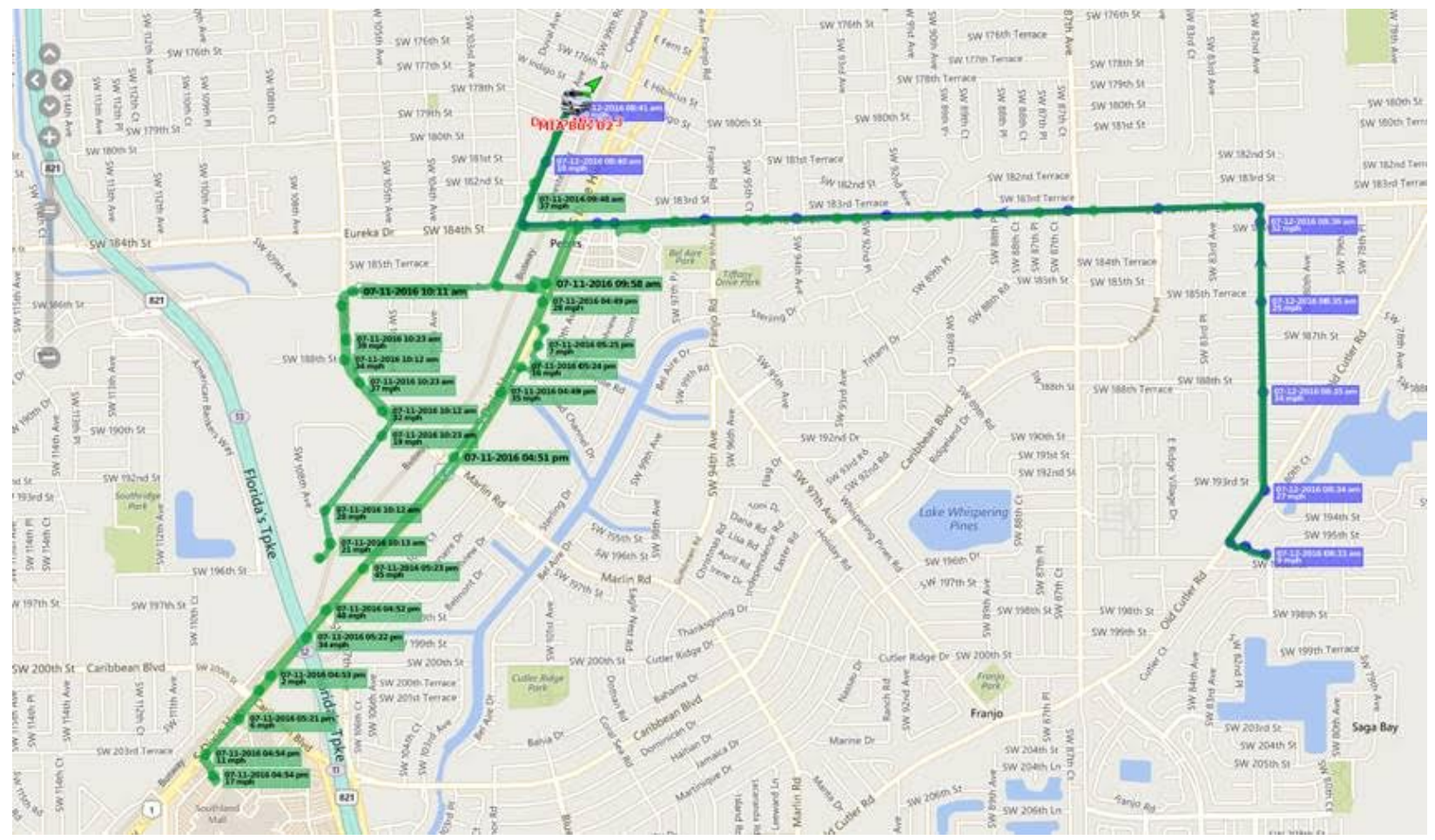

Figure A - 7. WBC Fleet map view

WBC Fleet also features a mobile application (Figure A - 8), which allows fleet managers to track vehicle locations wherever they are. The application can be configured to receive automatic notifications regarding speeding, idling, maintenance, or other issues. 

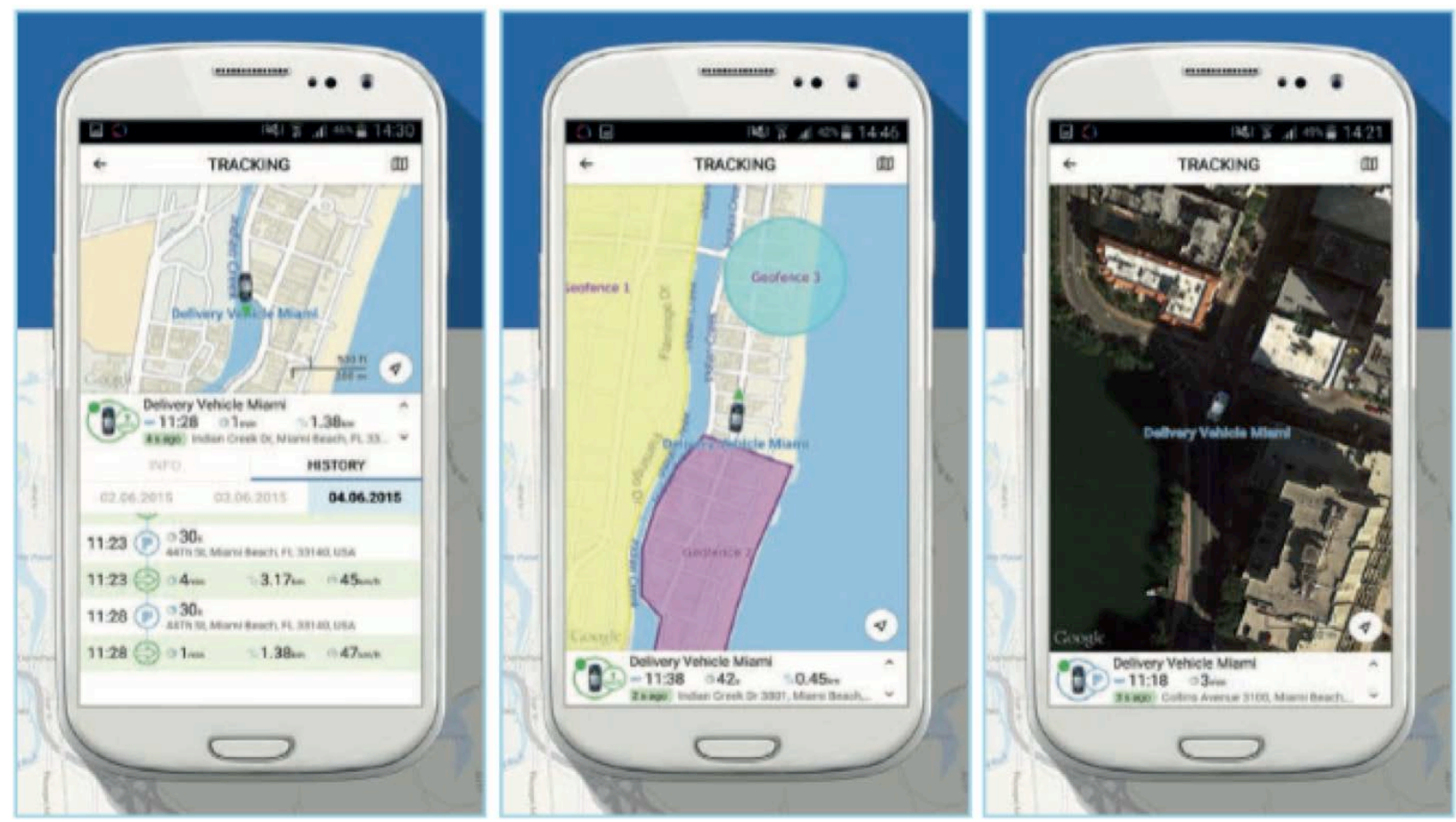

Figure A - 8. WBC Fleet mobile application views

WBC Fleet provides an eco-driving score that combines metrics on quick acceleration, hard braking, aggressive cornering and turning, speeding, and driving recklessly. It includes a customizable field for the fleet managers to capture an additional driving characteristic, and WBC automatically calculates the inputs into a single efficiency score.

WBC Fleet allows fleet managers to customize notifications, such as when a vehicle is speeding or idling, triggers the alarm or a sensor trigger, or arrives at a certain location. These notifications can take place immediately or be set daily or to some other period. The reports can be set for individual vehicles or a group of vehicles. They can note every time the vehicle exceeds the speed limit, or they can provide notifications only when a vehicle exceeds the speed limit by a certain amount or for a given period, such as $10 \mathrm{mph}$ over the speed limit for more than 2 minutes.

WBC Fleet has a variety of cybersecurity protections. The firmware is configured as read-only, although there is an option to update firmware over the air given the correct permissions from the network. That capability can be disabled if indicated by the client. Another option to ensure security is to set up a private access point name (APN) for the devices. All the systems use a firewall, user-generated encrypted password, and intrusion prevention system.

\section{AT\&T}

GSA awarded a blanket purchase agreement (BPA) to AT\&T for its telematics solution in 2016. The award offers two system options, one for GPS tracking - including speed, location, idling, and periodic maintenance - and another that also includes vehicle diagnostics, fuel consumption, and emissions data where available. The diagnostic system includes vehicle efficiency scorecards and DTCs. More information about the BPA can be found on the GSA Fleet website (https://www.gsa.gov/portal/content/102676). 
AT\&T currently uses a Webtech system, which is more similar to WBC Fleet than to DriveCam. It provides a user interface that tracks current and past vehicle locations, alerts fleet managers according to custom settings (such as any time a speed exceeds $80 \mathrm{mph}$ ), and provides custom reports, driver logs, and dashboards (Figure A - 9). Fleet customers can compare speeds to posted limits for an extra $\$ 1$ per vehicle-month. Through the BPA, AT\&T reports data every 2 minutes, although the ping rate can be set more frequently to provide more granular data. Data are stored in the live web portal for 15 months, and they are archived indefinitely. At any time, fleet managers can download summed totals, such as hard braking events in a given month or mileage from an odometer. The reports can also be set to provide these data, fuel consumption, and fuel economy on a periodic (e.g., monthly) basis. AT\&T can automate data feeds with an FMIS using an API. It can also layer in key fobs to identify particular drivers, which may be valuable for federal vehicles, because hundreds of people may drive a given car over its lifetime. AT\&T can also set up geofences such as base parking lots or landmarks such as alternative fueling stations.

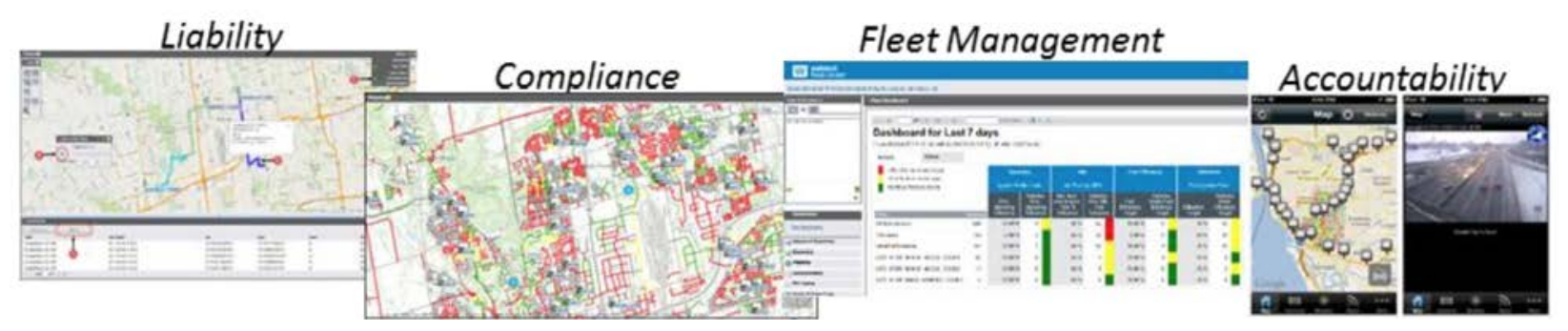

Figure A - 9. AT\&T Webtech user interfaces (AT\&T Fleet Management 2017)

AT\&T also sells Geotab systems. Geotab uses proprietary hardware in the GO7 device with a universal harness that plugs directly into the vehicle OBD-II (Figure A - 10). The platform is designed with cybersecurity in mind, using authentication, encryption, and message integrity verification. Each device has a unique ID, and its security key is not static or repeated from other devices to prevent spoofing the device in communication to the network (Geotab 2017b). The federal solution also uses a private APN.

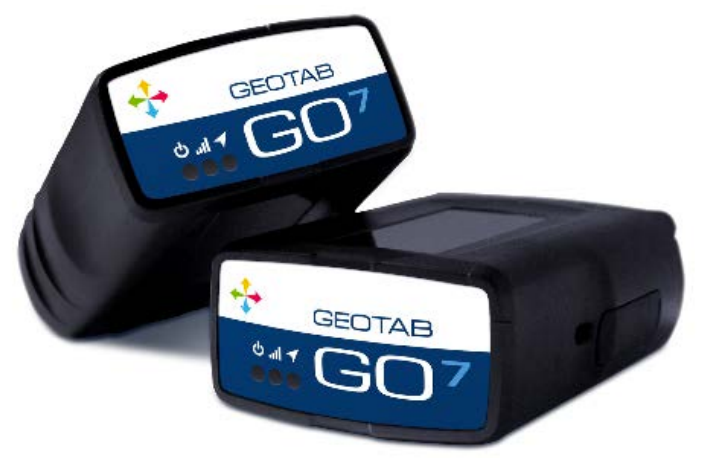

Figure A - 10. Geotab GO7 device (Geotab 2017b)

Geotab has a different data-collection method as well, called device-side curve logic. Instead of using a constant ping rate to gather data periodically (such as every 2 minutes), it monitors the vehicle second by second but only transmits changes in vehicle behavior, such as accelerating or braking. This provides very granular data. 
Geotab can benchmark driving behavior to show trend lines in speeding, idling, and other efficiency metrics over a few months or a year. Geotab also has an in-vehicle driver behavior management tool that encourages safe driving in real time. Furthermore, fleet managers can outfit drivers with individual identifications to let the fleet managers better track drivers. Geotab also features reports on fuel use, driver safety, and cost savings as well as a scorecard based on driver risk (Figure A - 11).

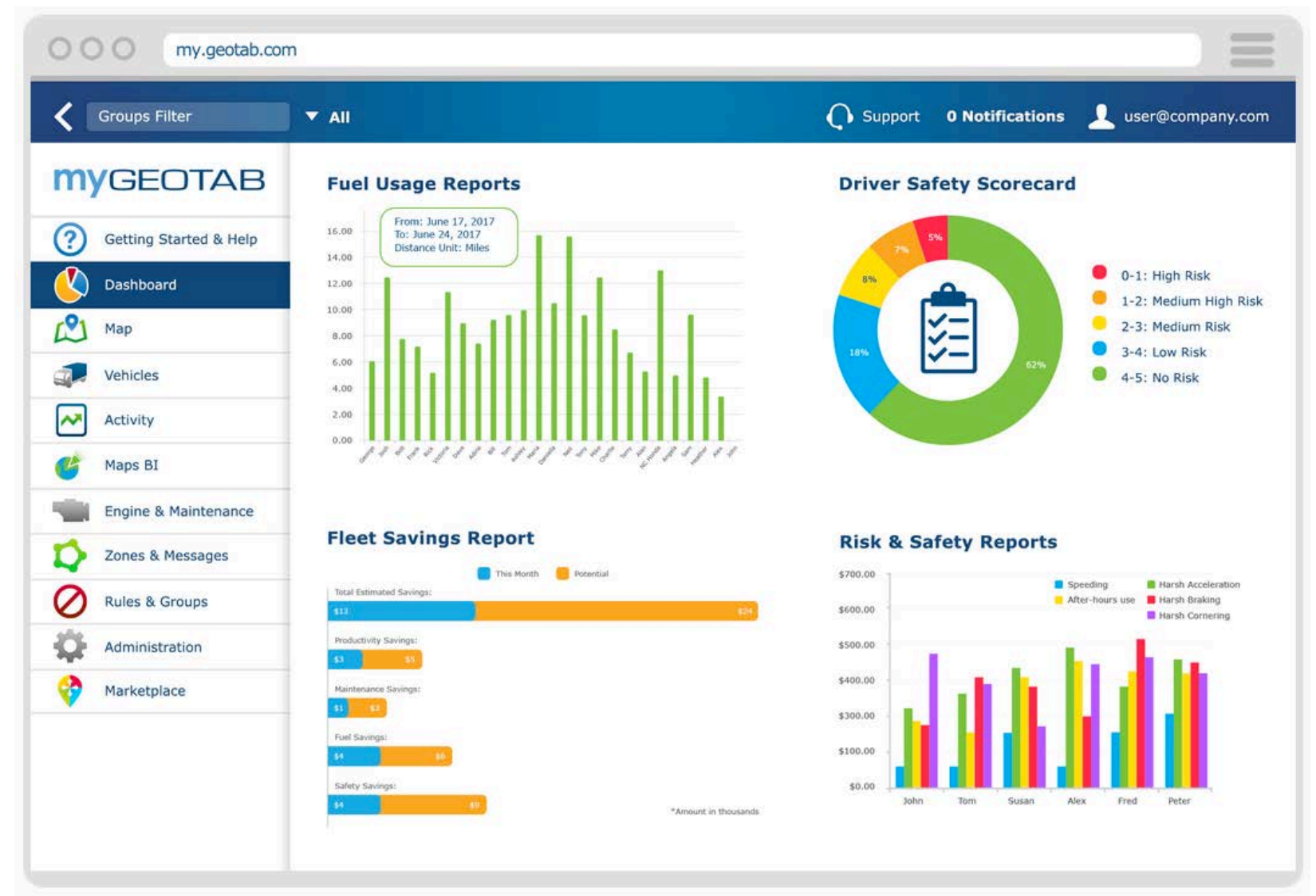

Figure A - 11. Geotab Dashboard interface (Geotab 2017c)

Geotab is also working with cities to apply big data and machine learning to manage traffic patterns and infrastructure planning (Jean Pilon-Bignell, Geotab, personal correspondence with author, September 19, 2017). For example, it can determine the average speed at specific locations along roads throughout the day to identify traffic bottlenecks or segments where speed limits do not align with speeds driven. It can also identify poor road conditions, including potholes, using vertical-axis accelerometer data. By geolocating collisions, it can also identify dangerous roadways and hazardous intersections. Agencies can use these data to manage military installations and federal campus settings, determining where speed limits should be adjusted, stop signs installed, roads repaired, or speed bumps installed.

\section{Verizon}

Prior to GSA's contract with AT\&T beginning in 2016, federal agencies could purchase Verizon NetworkFleet telematics through a GSA BPA. At least one Marine Corps fleet is outfitted with 
Verizon NetworkFleet systems. Verizon NetworkFleet provides similar services to the AT\&T Webtech and WBC Fleet systems, but it does not use video recording like Lytx DriveCam.

Verizon acquired two telematics systems in 2016: Fleetmatics and Telogis. With these additions, Verizon now offers a variety of products in the fleet sector (as well as applications in the insurance and consumer sectors). ExpressFleet targets government customers and smaller private fleets, the 5500 series includes additional fleet services like hours of service monitoring and can integrate with fuel cards, and Asset Guard tracks trailer locations. Fleetmatics Reveal focuses on GPS tracking, geofences, quantifying wasted dollars on fuel costs and engine hours, and fuel consumption tracking, while Fleetmatics Work provides maintenance information to vehicle technicians and tracks work performed on the vehicles.

Also in the product lineup is Telogis, which Verizon markets as its highest-end system. Telogis has OEM partners - such as Ford, GM, Volvo Trucks, Mack, Hino, and Isuzu — which enables easier integration with its proprietary vehicle codes. Telogis includes a comparison between planned routes and actual routes, in-vehicle alerts for the driver, and integration in some cases with OEM hardware.

As in the greater telematics industry, many of the products overlap in terms of basic functionality but can be distinguished by specific analytical capabilities and user interface. Fleet managers considering a telematics solution should review products with multiple providers before finding the system most suitable to their needs.

The Verizon NetworkFleet systems deployed in the federal fleet predate the acquisition of Fleetmatics and Telogis. The NetworkFleet system shares many similar features with WBC Fleet, AT\&T Webtech, Geotab, and Verizon's more recent acquisitions. It tracks vehicle locations (Figure A - 12), provides geofences, measures speeding and idling, tracks mileage and fuel use, and reports DTCs. Users can set up daily or weekly reports identifying speeding, idling, or other events. They can also set parameters to the results, such as more than 15 minutes of idling at a time or driving more than $10 \mathrm{mph}$ above the speed limit averaged over at least two minutes. 


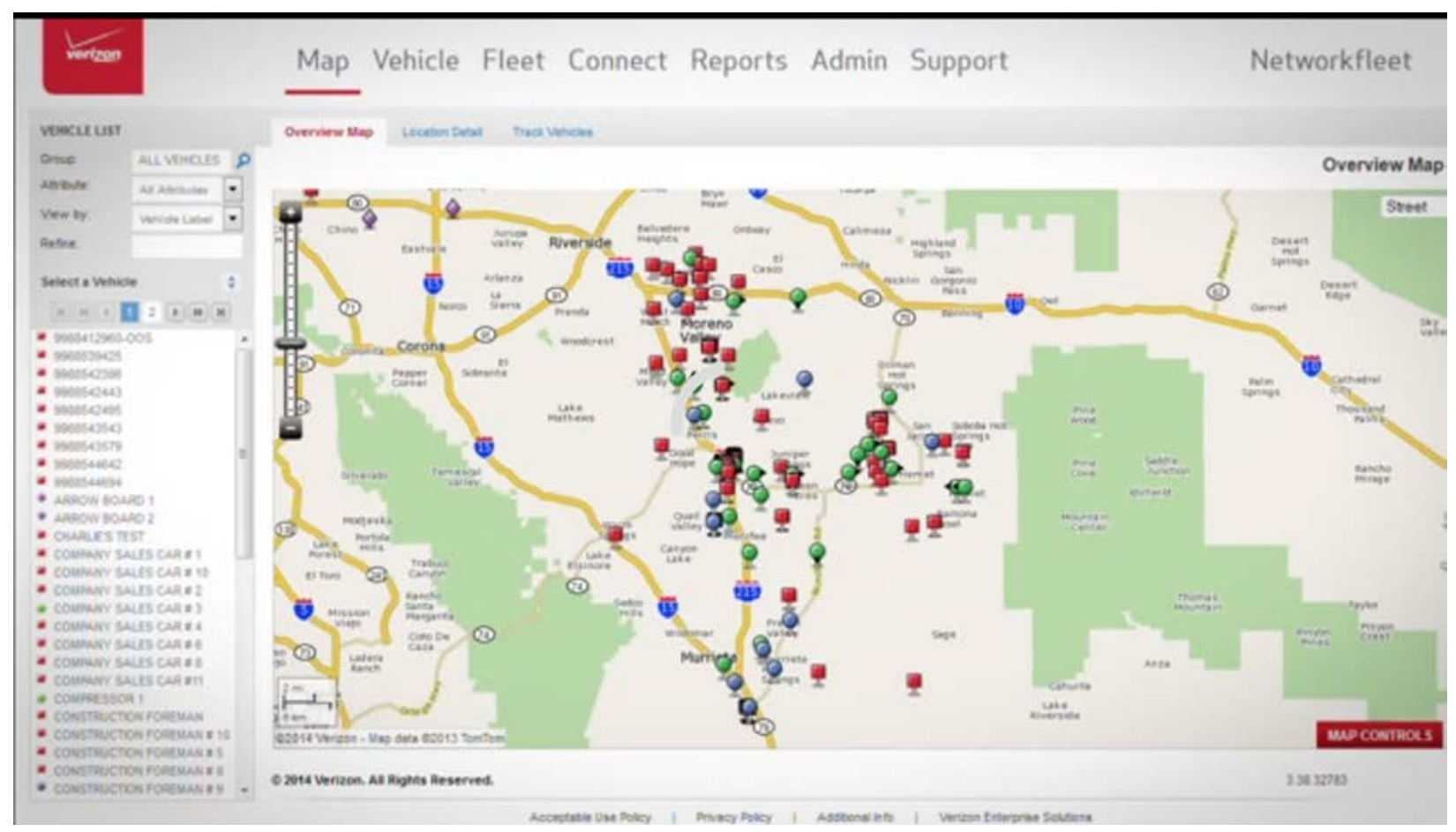

Figure A - 12. Verizon NetworkFleet vehicle location map (Automotive Fleet 2015) 